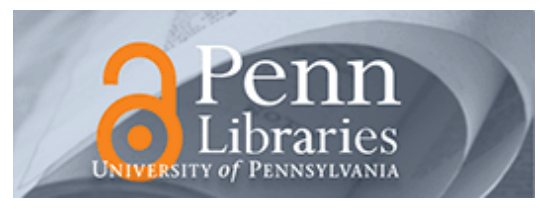

University of Pennsylvania

ScholarlyCommons

Publicly Accessible Penn Dissertations

2012

\title{
Evaluating the Effects of Child Care Policies on Children's Cognitive Development and Maternal Labor Supply
}

Andrew Griffen

University of Pennsylvania, andrew.griffen@gmail.com

Follow this and additional works at: https://repository.upenn.edu/edissertations

Part of the Labor Economics Commons

\section{Recommended Citation}

Griffen, Andrew, "Evaluating the Effects of Child Care Policies on Children's Cognitive Development and Maternal Labor Supply" (2012). Publicly Accessible Penn Dissertations. 515.

https://repository.upenn.edu/edissertations/515

This paper is posted at ScholarlyCommons. https://repository.upenn.edu/edissertations/515

For more information, please contact repository@pobox.upenn.edu. 


\title{
Evaluating the Effects of Child Care Policies on Children's Cognitive Development and Maternal Labor Supply
}

\author{
Abstract \\ To explore the role of child care policies in the development of early cognitive skills, I embed a value- \\ added cognitive achievement production function into a dynamic, discrete choice model of maternal labor \\ supply and child care decisions. I use the model to explore how two types of child care policies, Head \\ Start and child care price subsidies, affect child care use and quality decisions and how those decisions \\ in turn affect cognitive achievement. To estimate the model, I use rich panel data from the Early \\ Childhood Longitudinal Survey - Birth cohort (ECLS-B). There are three key findings: (1) Expanding Head \\ Start to children who are currently not eligible has beneficial effects on cognitive achievement, because \\ even children from relatively high quality home environments spend significant amounts of time in low \\ quality child care. An universal expansion of Head Start increases average cognitive achievement scores \\ by 0.21 standard deviations at kindergarten entry. (2) For the typical subsidy-eligible population, child care \\ subsidies have small positive effects on cognitive skills by inducing children from low quality home \\ environments to enter relatively higher quality child care environments. Six months of exposure to a \\ subsidy program increases cognitive achievement scores by .036 standard deviations on average. (3) \\ Without Head Start the black-white achievement gap at kindergarten entry increases by 9 percent and \\ child care subsidies decrease the black-white achievement gap at kindergarten entry by 3 percent. \\ Degree Type \\ Dissertation \\ Degree Name \\ Doctor of Philosophy $(\mathrm{PhD})$ \\ Graduate Group \\ Economics \\ First Advisor \\ Petra Todd \\ Keywords \\ Child care subsidies, Child development, Economics of education, Head Start, Labor economics \\ Subject Categories \\ Economics | Labor Economics
}




\title{
EVALUATING THE EFFECTS OF CHILD CARE POLICIES ON CHILDREN'S COGNITIVE DEVELOPMENT AND MATERNAL LABOR SUPPLY
}

\author{
Andrew S. Griffen
}

\section{A DISSERTATION}

\author{
in \\ Economics \\ Presented to the Faculties of the University of Pennsylvania \\ in \\ Partial Fulfillment of the Requirements for the \\ Degree of Doctor of Philosophy \\ 2012 \\ Petra E. Todd \\ Alfred L. Cass Term Professor of Economics \\ Supervisor of Dissertation \\ Dirk Krueger, Professor of Economics \\ Graduate Group Chairperson
}

\section{Dissertation Committee}

Petra E. Todd, Alfred L. Cass Term Professor of Economics

Kenneth I. Wolpin, Walter H. and Leonore C. Annenberg Professor in the Social Sciences

Flavio Cunha, Assistant Professor of Economics 


\section{Acknowledgements}

I certainly would not have been able to complete my dissertation without the support of my committee; Petra Todd, Ken Wolpin and Flavio Cunha. Their discussions, suggestions and criticisms improved my research immeasurably. I also received many helpful comments from other faculty members including Hanming Fang, Cecilia Fieler and Holger Sieg. The job market was an interesting time and again I received many thoughtful suggestions and questions. I am thankful for all the places that considered me for a job and for taking the time to fly me out. Specifically, I would like to thank the University of Tokyo for actually giving me a job. It's a great opportunity for me on many levels.

I would like to gratefully acknowledge dissertation support from the Institute of Education Sciences, which made the completion of my Ph.D. much less painful. It also tilted my research towards more of an education focus, which I think is an exciting direction for economics. In particular, I owe Rebecca Maynard a debt of gratitude for the foundation of the IES program at Penn and for our co-authored work.

Finally, I would like to thank family, friends and colleagues. My mother and grandfather were both particularly supportive of my academic endeavors. Academia seems to run in the family. My grandmother sent countless care packages, which were much appreciated. Friends and colleagues helped in various ways. Some provided support, advice and distraction to get through difficult

times. Others helped specifically with research and my project benefited greatly from being able to interact with them. A small list of names of people that 
I am grateful to in one way or another: Chin-Chih Chen, Cecilia Calderon, Rob Lieberthal, Gil Shapira, Clement Joubert, Laura Hawkinson, Michelle Kim, Hans Holter, Moran Blueshtain, Anton Badev, Amnon Buxboim, Andrea Waddle, Dan Waddle, Indraneel Chakraborty, Panos Stavrinides, Nirav Mehta, and Ellie Harvill. The list could easily be several pages long. Thank you so much to everyone. Finally, I would like to dedicate this work to Tess. You were really special to me and I'm sorry I couldn't be there for you more. The end was very sad but I'll keep the memories with me forever. 


\section{ABSTRACT \\ EVALUATING THE EFFECTS OF CHILD CARE POLICIES ON \\ CHILDREN'S COGNITIVE DEVELOPMENT AND MATERNAL LABOR SUPPLY \\ Andrew S. Griffen \\ Petra Todd}

To explore the role of child care policies in the development of early cognitive skills, I embed a value-added cognitive achievement production function into a dynamic, discrete choice model of maternal labor supply and child care decisions. I use the model to explore how two types of child care policies, Head Start and child care price subsidies, affect child care use and quality decisions and how those decisions in turn affect cognitive achievement. To estimate the model, I use rich panel data from the Early Childhood Longitudinal Survey - Birth cohort (ECLS-B). There are three key findings: (1) Expanding Head Start to children who are currently not eligible has beneficial effects on cognitive achievement, because even children from relatively high quality home environments spend significant amounts of time in low quality child care. An universal expansion of Head Start increases average cognitive achievement scores by 0.21 standard deviations at kindergarten entry. (2) For the typical subsidy-eligible population, child care subsidies have small positive effects on cognitive skills by inducing children from low quality home environments to enter relatively higher quality child care environments. Six months of exposure to a subsidy program increases cognitive achievement scores by .036 standard deviations on average. (3) Without Head Start the black-white achievement gap at kindergarten entry increases by 9 percent and child care subsidies decrease the black-white achievement gap at kindergarten entry by 3 percent. 


\section{Contents}

1 Introduction 1

2 Literature $\quad 8$

3 Model 12

Description . . . . . . . . . . . . . . . . 12

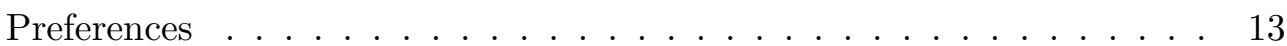

Child Care . . . . . . . . . . . . . . . . . . 13

Head Start . . . . . . . . . . . . . . . . . . 14

Home Quality . . . . . . . . . . . . . . . . . 15

Cognitive Achievement Production Function . . . . . . . . . . . . . 15

Wages and Income . . . . . . . . . . . . . . . . 16

Fertility and Divorce . . . . . . . . . . . . . . 17

Shocks and State Space . . . . . . . . . . . . . . 17

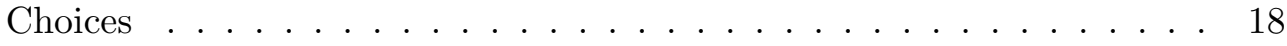

Mother's Problem . . . . . . . . . . . . . . . . . 19

Terminal Value . . . . . . . . . . . . . . . . . . . 19

Unobserved Heterogeneity . . . . . . . . . . . . . . . . . . 20

Solution Method . . . . . . . . . . . . . . . . . 20

4 Measuring Child Care and Home Quality 22

5 Data $\quad 25$

$\begin{array}{llr}6 & \text { Estimation } & 28\end{array}$

Objective Function . . . . . . . . . . . . . . . . 30 
Standard Errors . . . . . . . . . . . . . . . . . . . . 31

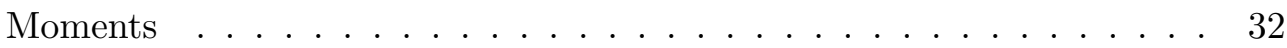

7 Child Care Subsidies $\quad 41$

Institutional Details . . . . . . . . . . . . . . . . . . . 41

Modeling Child Care Subsidies . . . . . . . . . . . . . . . . . . 43

8 Estimation Results 46

Parameters Estimates . . . . . . . . . . . . . . . 46

Model Fit . . . . . . . . . . . . . . . . . . . . . 48

$\begin{array}{ll}\text { Counterfactuals } & 51\end{array}$

Head Start . . . . . . . . . . . . . . . . . . 51

Child Care Subsidies . . . . . . . . . . . . . . . . . 54

$\begin{array}{ll}\text { Conclusions } & 58\end{array}$

$\begin{array}{lr}\text { Appendix } & 59\end{array}$

Appendix A: Summary Statistics . . . . . . . . . . . . . . 59

Appendix B: Functional Forms . . . . . . . . . . . . . . . 63

Appendix C: Parameters and Model Fit . . . . . . . . . . . 67

Appendix D: Counterfactuals . . . . . . . . . . . . . . . 89

$\begin{array}{ll}\text { Bibliography } & 95\end{array}$ 


\section{List of Tables}

$\begin{array}{lr}\text { Summary Statistics } & 59\end{array}$

A.1 Descriptive Statistics . . . . . . . . . . . . . . . . 59

A.2 Home Quality Measurements . . . . . . . . . . . . . . . . 60

A.3 Child Care Quality Measurements . . . . . . . . . . . . . . . . . 61

A.4 Sample Selection Criteria . . . . . . . . . . . . . . . . . 62

$\begin{array}{ll}\text { Parameters and Model Fit } & 67\end{array}$

C.1 Parameter Estimates . . . . . . . . . . . . . . . . . 67

C.2 Ancillary Statistics . . . . . . . . . . . . . . . . 70

C.3 Basic Statistics . . . . . . . . . . . . . . . . . . . . 71

C.4 Average Cognitive Skills By Household Characteristics . . . . . . . . . . 72

C.5 Percentage in Child Care By Household Characteristics . . . . . . . . . . 73

C.6 Average Child Care Quality By Household Characteristics . . . . . . . . 74

C.7 Average Child Care Price By Household Characteristics . . . . . . . . . . 74

C.8 Head Start Participation By Household Characteristics . . . . . . . . . . 75

C.9 Average Home Quality By Household Characteristics . . . . . . . . . . 76

C.10 Percentage in Labor Force By Household Characteristics . . . . . . . . . 77

C.11 Distribution and Transition of Decisions . . . . . . . . . . . . 78

C.12 Average Wage By Mother's Characteristics . . . . . . . . . . . . . . 79

C.13 Average Income By Father's Characteristics . . . . . . . . . . . . . . . 80

C.14 Average Number of Younger Children By Household Characteristics . . 81

C.15 Average Number of Older Children By Household Characteristics . . . . 83

C.16 Percent Married By Household Characteristics . . . . . . . . . . . 85 
D.1 Model Validation: Model Experiment vs. Head Start Impact Study . . . 89

D.2 Head Start Counterfactuals . . . . . . . . . . . . . . . . . . . 90

D.3 The Effect of Head Start Policies on the Black-White Achievement Gap . 91

D.4 Subsidy Counterfactuals I . . . . . . . . . . . . . . . . . . . . . . 92

D.5 Subsidy Counterfactuals II . . . . . . . . . . . . . . . . . . . . 93

D.6 The Effect of Child Care Subsidies on the Black-White Achievement Gap 94 


\section{List of Figures}

F.1 Average Number of Young Children By Mother's Age . . . . . . . . . . . 82

F.2 Average Number of Older Children By Mother's Age . . . . . . . . . . . 84

F.3 Percent Married By Mother's Age . . . . . . . . . . . . . . . 85

F.4 Cognitive Gaps by Maternal Education and Child's Age . . . . . . . . . . 86

F.5 Cognitive Gaps by Child's Age and Race . . . . . . . . . . . . . . 87

F.6 Child Care Quality by Child's Age and Race . . . . . . . . . . . . . 88 


\section{Chapter 1}

\section{Introduction}

Early cognitive achievement test scores are important because early test scores have been shown to be related to later achievement test scores, final educational attainment and labor market success (Currie and Thomas, 1999; Chetty et al., 2010). Policies to improve cognitive skills or to close early racial or socioeconomic cognitive achievement gaps become costlier as children age and interventions are more effective in early childhood (Heckman and Masterov, 2007). Theories of childhood development emphasize that stimulating environments foster the development of cognitive skills (Case, 1992), which implies that policies to improve cognitive skills should focus on where children spend time and the quality of those environments. In the U.S., children spend on average a substantial fraction of time outside the home, even at young ages. Among 9 month old children, for example, $49.7 \%$ spent some time in child care and those children spent on average 32.25 hours / week in nonparental care. ${ }^{1}$ Research consistently finds positive associations between child test score outcomes and child care quality (Love et al., 1996), so improving child care experiences is seen as a potentially effective means of improving cognitive skills for at risk children.

In this paper, I study the effectiveness of two kinds of child care policies, Head Start and child care price subsidies, both how the policies affect children's child care experiences and their subsequent effects on cognitive skills. Head Start is a

\footnotetext{
${ }^{1}$ Author's calculations, Early Childhood Longitudinal Survey - Birth Cohort (ECLS-B).
} 
free, federally funded preschool program for poor children that aims to "promote school readiness by enhancing the social and cognitive development of children." ${ }^{2}$ A randomized controlled trial of Head Start demonstrated that the program has positive effects on cognitive achievement at kindergarten entry that fade-out by 1st grade (Head Start Impact Study 2005), which has led to calls to cut Head Start funding or to change how Head Start is implemented. ${ }^{3}$ In the face of budgetary pressure, understanding who should be eligible for Head Start and how to design Head Start to improve cognitive skills are important questions to answer in order to improve the program's effectiveness. ${ }^{4}$

The second type of policy that I study, child care price subsidies, provided through the Child Care and Development Fund (CCDF), give income eligible working mothers a voucher for child care services. Child care price subsidies are designed primarily to support the labor force participation of women (Adams and Rohacek 2002). How to incorporate child development goals into the design of child care subsidies has been an issue at least since the the 1970s (Heckman 1974). Child care subsidies have an ambiguous impact on child outcomes because the subsidies can simultaneously increase the demand for child care quality, which improves cognitive skills, and incentivize the use of child care, which can lower cognitive skills if the home environment is more productive. Recent reduced form

\footnotetext{
${ }^{2}$ For the quote, see the program description at the Office of Head Start website.

${ }^{3}$ See the discussion during the recent budget debate: "Cuts to Head Start Show Challenge of Fiscal Restraint" in the NY Times March 10, 2011. http://www.nytimes.com/2011/03/11/us/politics/11headstart.html

${ }^{4}$ See Gibbs, Ludwig and Miller (2011) for a discussion about "fade out" and whether fade out perhaps represents catch up. In a Cunha-Heckman production function with complementarities over time, another possibility is that fade out is a result of lack of investment in the post kindergarten period. In this case, Head Start might still be the correct type of intervention but the optimal policy might space investment out over more periods for Head Start eligible children. There is also evidence that Head Start has longer term impacts on noncognitive outcomes (See Garces et al., 2002; Ludwig and Miller, 2007; Deming, 2009). To the extent that cognitive impacts are correlated with noncognitive impacts, analyzing the impact of Head Start design and coverage on cognitive outcomes would still be applicable.
} 
empirical research indicates that subsidies have a harmful effect on children's cognitive outcomes (Herbst and Tekin 2010; Hawkinson, Griffen, Dong and Maynard, 2011). An open question is to understand the mechanisms through which child care subsidies affect children's cognitive achievement, to elucidate how child care subsidy policy parameters affect choices and to reassess the design of subsidies.

To investigate the effects of these two child care policies on cognitive achievement and maternal labor supply, I embed a cognitive achievement production function into a dynamic discrete choice model of child care and maternal labor supply decisions. In each model period (every six months), mothers receive a wage offer and a price-quality offer for child care services. Fathers, when present, contribute to household income. Eligible families have an additional Head Start quality offer in their choice set. The mother makes decisions about whether to stay home, work part-time or work full-time and, for up to two children age 5 or less, whether to use child care part-time, full-time, or not at all. The time spent in child care, the quality of child care and the quality of the home environment are inputs into the value-added cognitive achievement production function. The child's cognitive skills and the mother's labor market experience evolve endogenously and the mother faces trade-offs between consumption, leisure, the cognitive development of her children and the accumulation of labor market experience. Mothers in the model face uncertainty in the form of shocks to wage offers, husband's income, the cognitive skills of children, home quality, the price and quality of child care, and preferences for leisure and child care. Marital status and fertility are modeled as stochastic processes.

A dynamic model is a natural setting for examining both the short-term and long-term effects of alternative child care policies. Cognitive skills develop over time and the value-added cognitive achievement production function captures the 
dynamic nature of skill accumulation (Cunha and Heckman 2007, 2008). Female labor market experience also accumulates over time. When making a labor supply decision, the mother weighs not only current consumption and leisure but also the effect of working on future labor market experience and her children's cognitive achievement. On child care policy, Blau (1999) emphasizes "the trade-off faced by policymakers between the goals of improving child well-being and increasing economic self-sufficiency." Heckman (1974) discusses how the evaluation of child care subsidy programs is complicated not only by the fact that subsidies have work requirements but also because different features of the subsidies change who participates and what decisions they make. My modeling approach allows a realistic representation of different child care policy parameters and constraints and of how they influence program participant outcomes.

To estimate the model, I use data from the ECLS-B, a nationally representative panel of 14,000 children born in the United States in 2001. Children were followed until kindergarten entry and extensive information was collected about the children's home environments, child care environments and scores on cognitive assessments. I define and measure the "quality" of the child's home and child care environments in a way that is consistent with other early childhood research. The data also contain information on the wages and labor force participation decisions of mothers, husbands' income, hours spent in child care, prices paid for child care services, marital status and other characteristics of the child's parents.

I estimate the model parameters using the Method of Simulated Moments (McFadden 1989). I simulate the model and match statistics from the simulated data to statistics from the ECLS-B. Although the model contains multiple children per family, the data only contain information on a single child. To ad- 
dress this limitation, I use an unconditional simulation approach that simulates mothers from their first birth. I integrate over unobserved elements of the statespace and mimic the ECLS-B sample selection procedure by selecting sequences of shocks such that the mother has a birth in the same year that the ECLS-B collected data. I compare predictions of the model about the intra-sibling correlation of cognitive skills and birth order effects on cognitive skills to evidence from external data sets.

Using the estimated model, I study the effects of Head Start on the cognitive achievement of children. As a model validation exercise, I evaluate Head Start in my model using the design of the Head Start Impact Study (HSIS), a randomized controlled trial of Head Start. The results are consistent with those of the HSIS. I also use the model to perform evaluations of changes to Head Start including removing Head Start for two years (an arm that the HSIS did not evaluate) and replacing Head Start with equivalent cash transfers to eligible families. I find that in-kind transfers through Head Start increase cognitive skills at kindergarten entry by 0.13 standard deviations relative to providing parents with the money directly. I then evaluate the effects of expanding Head Start services to current non-eligible recipients. I find that increasing Head Start access improves cognitive achievement because many non-eligible children spend significant amounts of time in low quality child care. In particular, a universal Head Start program increases average cognitive achievement scores by 0.15 standard deviations at kindergarten entry. I also document that the current Head Start program helps to close the black-white achievement gap; without Head Start, the current black-white achievement gap would be 9 percent larger at kindergarten entry. This finding reflects both the relative productivity of Head Start compared to other forms of child care and the differential access to Head Start by black 
children, because of family income eligibility cutoffs.

I then use the model to study the effects of child care price subsidies on cognitive achievement and maternal labor force participation. In contrast to previous research, I find that for the typical subsidy-eligible population, child care subsidies have small positive effect on cognitive skills by inducing families to move children from low quality home environments to relatively higher quality child care environments. Six months of an offer of a child care subsidy program increases cognitive achievement scores by .043 standard deviations on average. I then consider changes to the design of the subsidy programs, by changing income eligibility cutoffs, the maximum reimbursement rate and family copayments, and document how these policy parameters affect cognitive skills, maternal labor supply, coverage and cost. I find that the most effective combination of policy parameters to improve cognitive skills targets the program to the very poor, sets the copay to 0 and makes the reimbursement rate generous. I also find that this configuration of program parameters has a large impact on maternal labor force participation, increasing labor supply by 36 percentage points. For the very poor, there do not appear to be trade-offs between labor supply and cognitive achievement goals. Finally, I find that child care subsidies can have a small positive effect on closing the black-white cognitive achievement gap. Specifically, I find that 6 months of a child care subsidy decreases the black-white achievement gap by 1.4 percent. The result obtains because black mothers are more likely to be eligible for subsidies based on their family income. The effect of using child care on cognitive achievement is potentially larger for black children than for white children. Black mothers offer lower home quality on average, so that the subsidy differentially increases the cognitive skills of black children who are induced into child care. 
The paper is organized as follows. In section 2, I review the related literature. I present the model in section 3 and discuss my measurement system for child care and home quality in section 4 . I discuss the data in section 5 and the estimation in section 6. In section 7, I review institutional details about child care subsidy policy in the U.S. and discuss in detail how I incorporate subsidies into the model. Section 8 describes the estimation results, section 9 presents the counterfactual results and section 10 concludes. 


\section{Chapter 2}

\section{Literature}

My paper contributes to a large literature on the cognitive achievement of children, child care subsidies, Head Start, and female labor supply. A multidisciplinary literature in psychology, education and economics examines the effect of child care use and quality on cognitive achievement outcomes. Love et al. (1996) present a review of this research and its findings that child care quality is positively associated with child cognitive achievment. Blau (2000) provides an extensive review of child care subsidy programs. Heckman (2006) argues for the use of early interventions to improve both cognitive and noncognitive outcomes of children. ${ }^{5}$ Child care policies are one such policy intervention. The quality of the home environment predicts child outcomes across a wide range of studies and empirical strategies (Bradley and Caldwell, 1980; Leibowitz, 1974; Murnane et al. 1981; Todd and Wolpin, 2007; Cunha and Heckman 2008). Todd and Wolpin (2003) and Cunha and Heckman (2007) discuss theoretical issues on modeling the cognitive achievement production function. Blau and Currie (2006) have an extensive review of child care policies, a theoretical discussion of the effects of subsidies and an empirical survey of the literature. Blau and Currie call for research that studies both the take-up of child care subsidies and interactions between the public and private provision of child care services. Almond and Currie (2011) survey a large literature on the development of human capital before age

\footnotetext{
${ }^{5}$ See also Carneiro and Heckman (2003); Cunha, Heckman, Lochner and Masterov (2006); Cunha and Heckman (2010).
} 
5 including early child care interventions.

This paper builds on the work of Bernal (2008) who also estimates a dynamic discrete choice model of maternal labor supply and child care decisions that incorporates the cognitive achievement of children. ${ }^{6}$ She estimates the effects of child care time inputs and maternal employment on the cognitive achievement of children for married women with only one child in NLSY-79 and finds that an additional year of child care and maternal employment reduces cognitive achievement test scores by -0.13 standard deviations. My paper extends her work in a number of important dimensions. First, Bernal focuses on child care time inputs but I focus on both child care time and quality decisions in the choice set and the production function, which brings the model much closer to the frontier in the child development literature. Bernal suggests incorporating child care quality into this class of models as an important qualifier to her empirical findings. Although I use my model to evaluate a much more specific class of child care policies, I discuss the similarity and differences between our findings in the results section. Second, besides child care quality, I allow a much richer choice set for the mothers; more hours of work decisions, more hours of child care decisions and the possibility of using Head Start, which is a prominent child care option for low-income families. Third, I include the possibility of both divorce and future fertility in the model, which not only expands the estimation sample but importantly changes how mothers value their expected future utility when making child care and employment decisions.

\footnotetext{
${ }^{6}$ Del Boca, Flinn and Wiswall (2010) also estimate a behavioral model with a cognitive achievement production. They focus on maternal and paternal time inputs as opposed to child care inputs and do not model heterogeneity in either home inputs or child care inputs. The ideal model would be a synthesis of these models that not only incorporates child care, employment, hours of home inputs but that would also recognize the heterogeneity in both children's child care and home experiences.
} 
I contribute to a small literature in economics on estimating cognitive achievement production functions with child care inputs. Bernal and Keane (2010) estimate a cognitive achievement production function jointly a model of child care choices and find that an additional year of child care and maternal employment reduces cognitive achievement by -0.14 standard deviations. Bernal and Keane (2011) estimate a cognitive achievement production function using exogenous changes in welfare eligibility and find negative effects of child care use on cognitive achievement. They also report that the effect depends on the type of care with formal care having no negative impact on cognitive achievement. Duncan (2003) estimates the impact of child care quality on cognitive outcomes and finds effect sizes of $0.04-0.08$ on the impact of child care quality on child outcomes. Blau (1997) estimates the effect of so-called "structural" measures of child care quality such as staff-child ratio and caregiver qualifications and reports that structural measures of quality have no consistent impact on child outcomes. His results suggest that regulation of child care through more easily observed structural measures of quality is not a fruitful strategy to improve child outcomes. $^{7}$ The interpretation of these results is that (1) child care on average negatively impacts cognitive skills, (2) some forms of child care such as more formal child care arrangements do not negatively impact cognitive achievement skills, (3) conditional on the number of hours of child care, improving the quality of child care experiences increases cognitive achievement and (4) process quality and not structural quality is the important feature of a child care environment. ${ }^{8}$

\footnotetext{
${ }^{7}$ On the other hand, Hotz and Xiao (2011) directly investigate the effects of child care regulations on child care quality and find that regulations increase child care quality (as measured by accrediation) and reduce the number of child care providers. These result would suggest that the cognitive skills for children in child care would increase and the cognitive skills of children crowded out of using child care could increase or decrease depending on the quality of their home or of an alternative child care provider not affected by regulation (such as a relative).

${ }^{8}$ I discuss the distinction between process and structural measures of quality in the section
} 
My work also contributes to the literature on child care subsidies and cognitive achievement. Both Herbst and Tekin (2010 a,b) and Hawkinson, Griffen, Dong and Maynard (2010) find negative impacts of subsidy receipt on child outcomes after controlling for unobserved determinants of achievement (Herbst and Tekin) and lagged achievement (Hawkinson et al). Neither paper explores the determinants of subsidy receipt nor the mechanisms through which subsidy receipt may affect cognitive achievement. These paper do not relate the design of child care subsidy to child outcomes or quantify the trade-offs between encouraging labor supply and improving cognitive achievement. Moreover, the negative impact of subsidy receipt on child outcomes is in conflict with some previous research in the literature including experimental evidence on child care vouchers (Huston et al. 2001). My model permits a realistic representation of child care policy parameters and constraints and I connect those policy parameters to both child cognitive achievement outcomes and maternal labor supply decisions.

Head Start has been an extensively evaluated program including a randomized controlled trial (Head Start Impact Study 2005) and a rigorous observational study using a within sibling estimation strategy (Currie and Thomas 1995). My model contributes to the Head Start literature by considering the effect of the existing Head Start program on a new population (if Head Start is expanded) or replacing Head Start with cash transfers (to test whether in-kind transfers or cash have larger impacts on cognitive skills). A model both clarifies the assumptions needed to estimate the effects of such programs, allows realistic modeling of eligibility constraints, and predicts how individuals will value a new good (Head Start) not previously in their choice set.

on Child Care and Home Quality. 


\section{Chapter 3}

\section{Model}

\section{Description}

The model begins when a mother first has a child and ends when she turns 45 .

Mothers can be married (or not), face the risk of divorce and can have more children as they age. Every 6 months the the mother makes a labor force decision and child care arrangement decisions for her children. For her labor supply decision, the mother receives a wage offer that depends on her characteristics and she can either stay home, work part-time or work full-time. For child care, the mother chooses, for each child younger than five, whether they attend child care part-time, full-time or stay at home. I define "child care" as any type of nonparental care and I define "home care" as care given by one of the child's parents in the child's home. ${ }^{9}$ In the model, child care varies in both quality and price. Families make a draw from the price/quality distribution for child care services and can choose whether to use child care at that price and quality. Children from eligible families also have the option to attend Head Start, which offers free child care for children from poor families. In the model, mothers face a skill production function with the quality of child care, the time spent in child care, and the quality of the home environment entering as inputs. The child's cognitive skills

\footnotetext{
${ }^{9}$ Under this definition, child care encompasses relative care in the child's home, relative care outside the child's home, non-relative care in the child's home, and non-relative care outside the child's home such center based care, Head Start, and preschool. So any care not given by the child's parent would be considered "child care" even if the care occurred in the child's home. For example, a live-in nanny would be considered child care and not home care.
} 
and the mother's labor market experience evolve endogenously and the mother faces trade-offs between consumption, leisure, the cognitive development of her children and the accumulation of labor market experience. For the remainder of the model section, assume that I have a univariate measures of both home quality and child care quality. After the model section, I discuss how I measure home and child care quality in a way consistent with other early childhood research. To facilitate exposition of the model, I present the model without the specifications and I put the exact specifications in the appendix.

\section{Preferences}

The mother's contemporaneous utility function is given by:

$$
U\left(C_{t}, h_{L, t}, \theta_{t}^{1}, \theta_{t}^{2}, h_{c c, t}^{1}, h_{c c, t}^{2}, \epsilon_{L, t}, \epsilon_{c c, t} ; X_{t}\right)
$$

where her utility at time $\mathrm{t}$ depends on consumption, $C_{t}$, hours of leisure, $h_{L, t}$, the cognitive skills of child i, $\theta_{t}^{i}$, hours of child care for child i, $h_{c c, t}^{i}$ and shocks to the utility of leisure, $\epsilon_{L, t}$, and child care use, $\epsilon_{c c, t}$. In addition, the variables $X_{t}$ enter the model as marginal utility shifters by allowing some parameters to vary by marital status, the number of younger children, the number of older children and the age of the children. Direct preferences over hours of care are used to capture care use patterns by the children's ages.

\section{Child Care}

Each period the household receives a price-quality offer for child care services with the child care quality given by $q_{c c, t}$. I assume the child care quality offers 
are drawn from:

$$
\log \left(q_{c c, t}\right) \sim N\left(\mu_{q, c c}, \sigma_{q, c c}^{2}\right)
$$

The price for the child care quality draw is given by the hedonic equation:

$$
p_{c c, t}=p\left(q_{c c, t}, \epsilon_{p, t}\right)
$$

where $\epsilon_{p, t}$ is a shock to the price offer given a quality draw $q_{c c, t}$. The child can then attend child care of quality $q_{c c, t}$ for $h_{c c, t}^{i}$ hours at price per hour of $p_{c c, t}$.

\section{Head Start}

Families may be eligible for government provided care in the form of Head Start, which is a federal preschool program for children from poor families. Head Start is free so I put its price as $p_{H S}=0$. Let the distribution of Head Start quality be given by:

$$
\log \left(q_{H S, t}\right) \sim N\left(\mu_{q, H S}, \sigma_{q, H S}^{2}\right)
$$

An eligible child can then attend Head Start that offers child care of quality $q_{H S, t} \cdot{ }^{10}$ To be eligible for Head Start, children must be between the ages of 3 and 5 and the family income must be below a federal threshold, $\mathrm{I}^{H S}$, that depends on family size. Because Head Start is rationed I assume that eligible families receive a probabilistic offer of Head Start. Let $H_{t}^{i}$ equal 1 if child i has access to Head

\footnotetext{
${ }^{10} \mathrm{Head}$ Start is a part-time program so I assume that if families choose Head Start but also want to have full-time care that they use their first draw of price and child care quality to provide so-called "wrap around care."
} 
Start at time $t$ and zero otherwise:

$$
H_{t}^{i}=H\left(A_{t}^{i}, Y_{t} M_{t}+w_{t}\left(1000-h_{L, t}\right), \mid \text { Family } \mid, \epsilon_{H S}\right)
$$

where $A_{t}^{i}$ is the age of child $\mathrm{i}$ at time t.

\section{Home Quality}

Home quality is observed in the data and I model home quality at time t, $q_{h, t}$, as consisting of a household specific permanent component, $\omega$, and a transitory component, $\epsilon_{q h, t}$ :

$$
q_{h, t}=q_{h}\left(\omega, \epsilon_{q h, t}\right)
$$

\section{Cognitive Achievement Production Function}

Cognitive skills evolve endogenously according to the hours spent in child care, the quality of the child care arrangement, the quality of the home environment, the time spent at home and previous skills. The value-added cognitive skill production function is given by:

$$
\begin{array}{lr}
\theta_{t+1}^{i}=\omega\left(\theta_{t}^{i}\right)^{\gamma_{1, c}}\left(I_{t}^{i}\right)^{\gamma_{3, c}} e^{\epsilon_{c, t}^{i}} & \text { Production Function } \\
I_{t}^{i}=\left(2000-h_{c c, t}^{i}\right) q_{h, t}+\alpha h_{c c, t}^{i} \tilde{q}_{c c, t}^{i} & \text { Input }
\end{array}
$$

where $q_{h, t}$ is the quality of the home environment, $h_{h, t}^{i}$ is hours in the home environment, $\tilde{q}_{c c, t}^{i}$ is the quality of the child care environment for child i, $h_{c c, t}^{i}$ is hours in the child care environment, $\omega$ is a family specific permanent unobserved component and $\epsilon_{c, t}^{i}$ is child specific shock to cognitive skills. The input consists 
of quality hours spent in the home, $\left(2000-h_{c c, t}^{i}\right) q_{h, t}$, and quality hours spent in child care, $h_{c c, t}^{i} \hat{q}_{c c, t}^{i}$, where I assume that the child has 2000 hours in a period. ${ }^{11}$ The parameter $\alpha$ governs the substitutability of home and child care quality. For example, if $\alpha$ is less than one then one unit of home quality is more productive than one unit of child care quality. The value-added production function captures the cumulative and dynamic nature of cognitive achievement (Cunha and Heckman 2007, 2008). Current skills build on past skills through the parameter $\gamma_{1, c}$ so that lagged investment affects both current achievement and the productivity of current inputs.

\section{Wages and Income}

For married couples, the household enters the period knowing the father's education, $E_{f}$, and experience, $X_{f, t}$. The household draws an income shock $\epsilon_{I, t}$ and forms current period income. Similarly, the household draws a wage shock, $\epsilon_{w, t}$ and uses the mother's education, $E_{m}$, and experience, $X_{m, t}$, to form the current wage offer. I assume that the father transfers $\tau$ percent of his income to the mother, which is a parameter to be estimated. The income and wage functions are:

$$
\begin{aligned}
& w_{t}=w\left(\text { black }, E_{m}, X_{m, t}, \omega, \epsilon_{w, t}\right) \\
& I_{t}=I\left(\text { black }, E_{f}, X_{f, t}, \omega, \epsilon_{I, t}\right)
\end{aligned}
$$

I allow being black to directly affect the wage offer and I also have added a household specific permanent component, $\omega$, for the mother's wage and for the

\footnotetext{
${ }^{11} \mathrm{I}$ assume children are awake for 80 hours per week X 26 weeks (6 months), which is approximately 2000 hours.
} 
father's income. I assume that the father works full time so that his experience evolves deterministically. The mother's experience evolves according to her labor supply decision. The transition of the stocks of experience are given by:

$$
\begin{aligned}
& X_{m, t+1}=X_{m, t}+\frac{1000-h_{L, t}}{2000} \\
& X_{f, t+1}=X_{f, t}+.5
\end{aligned}
$$

\section{Fertility and Divorce}

In the model, the probability of a new child is given by $\pi_{b}=\pi_{b}\left(x_{t}^{b} ; \phi^{b}\right)$, which depends on observable characteristics $x_{t}^{b}$. I do not permit mothers to have more than two children less than five years of age. The probability of divorce is given by $\pi_{d}^{t}=\pi_{d}\left(x_{t, i}^{d} ; \phi^{d}\right)$, which depends on observable characteristics $x_{t}^{d}$ and is parameterized by $\phi^{d}$. I do not permit women with young children to remarry or to cohabitate with a non-biological father. ${ }^{12}$

\section{Shocks and State Space}

Before making labor force and child care decisions, the mother makes a child care quality and price draw, $q_{c c, t}$ and $p_{c c, t}$, a Head Start quality draw, $q_{H S, t}$, and a shock to Head Start availability to form $H_{t}^{i}$, which equal 1 if child i has access to Head Start at time t and 0 otherwise. The household also draws shocks to cognitive skills for each child $\mathrm{i}$ in the house, $\epsilon_{c, t}^{i}$, to home quality, $\epsilon_{q_{h}, t}$, to

\footnotetext{
${ }^{12}$ This selection criterion reduces the sample by $9 \%$. I also define a "father" as the child's biological father and being "married" in the model conflates cohabitation and marriage. Divorce then refers to the child's biological father exiting the household. Women who are "divorced" in the initial state space may have never been married or may have been cohabitating and then the father left before the child was 6 months old. Finally, there is a small group where the biological father is not in the house at baseline but later lives in the house. I exclude this group from the sample and I lose a further $5 \%$. Evidently women with young children are unlikely to remarry. See Table 4 for a complete list of sample selection criteria.
} 
the utility of leisure for the mother, $\epsilon_{L, t}$, to the utility of using child care, $\epsilon_{c c, t}$, to the woman's wage offer, $\epsilon_{w, t}$, and to income, $\epsilon_{I, t}$. Collecting the shocks in vector $\overrightarrow{\epsilon_{t}}=\left(\epsilon_{c, t}^{1}, \epsilon_{c, t}^{2}, \epsilon_{q_{h}, t}, \epsilon_{L, t}, \epsilon_{c c, t}, \epsilon_{w, t}, \epsilon_{I, t}\right)^{\prime}$, I assume the shocks are distributed multivariate normal:

$$
\overrightarrow{\epsilon_{t}} \sim N\left(0, \Sigma_{\epsilon}\right)
$$

I assume that the shock draws are independent over time. Define the state space at time t:

$$
\Omega_{t}=\left\{X_{f, t}, E_{f}, X_{m, t}, E_{m}, \text { black }, h_{L, t-1}, h_{c c, t-1}^{1}, h_{c c, t-1}^{2}, A_{t}^{1}, A_{t}^{2}, O_{t}, q_{c c, t}, p_{c c, t}, q_{h, t}, \overrightarrow{\epsilon_{t}}\right\}
$$

Let the nonstochastic part of the state space be $\bar{\Omega}_{t}$.

\section{Choices}

The household then makes decisions about the mother's hours of leisure and the child care hours for each child younger than age 5 . Let $h_{L, t}$ be a discrete variable that equals 0 if the wife stays at home in period t, 500 if she works part time and 1000 if she works full time. ${ }^{13}$ Hours of child care for child i, $h_{c c, t}^{i}$, can also equal either 0, 500 or 1000. For a family with Head Start in their choice set for child i, let $D_{H S}^{i}$ equal 1 if child i attends Head Start and 0 otherwise. In addition to the three labor supply choices, a household with two children can have up to five child care choices for each child (home, part-time child care, full-time child care, part-time Head Start or full-time Head Start) for a total of up to 75 choices.

\footnotetext{
${ }^{13}$ Because each period corresponds to 6 months, I assume that mothers working full-time work 40 hours per week times 24 weeks $=960$ hours. I round to 1000 hours for full-time work and set 500 hours as part-time work.
} 
Household with less children and who are not Head Start eligible have a smaller choice set.

\section{Mother's Problem}

Writing the problem recursively, the mother solves:

$$
\begin{gathered}
V_{t}\left(\Omega_{t}\right)=\max _{h_{c c, t}^{1}, D_{H S, t}^{1}, h_{c c, t}^{2}, D_{H S, t}^{2}, h_{L, t}}\{ \\
+\left(C_{t}+C_{\min }\left(1-M_{t}\right), \theta_{c, t}^{1}, \theta_{c, t}^{2}, h_{L, t}, h_{c c, t}^{1}, h_{c c, t}^{2}, \epsilon_{L, t}, \epsilon_{c c, t}\right) \\
\left.+\beta E V_{t+1}\left(\bar{\Omega}_{t+1}\right)\right\}
\end{gathered}
$$

subject to:

$$
\begin{gathered}
\tau I_{t} M_{t}+w_{t}\left(1000-h_{L, t}\right)=C_{t}+\sum_{i=1}^{2} p_{c c, t} h_{c c, t}^{i}\left(1-H_{t}^{i} D_{H S, t}^{i}\right) \\
+p_{c c, t} h_{c c, t}^{i} 1\left\{h_{c c, t}^{i}=1000\right\} H_{t}^{i} D_{H S, t}^{i} \\
\\
C_{t} \geq 0 \\
h_{c c, t}^{i}+h_{h, t}^{i}=2000 \\
h_{L, t}+h_{w, t}=1000
\end{gathered}
$$

\section{Terminal Value}

For the terminal value function, the woman needs to keep track of the cognitive skills for all of her children. At age 45 , the woman then attaches a utility value to the total stock of age five cognitive skills of all her children. Define $\theta_{c, t}^{T}$ as the total cognitive skills for all of the children in the house at time t. The stock of 
cognitive skills increases when children turn 5 according to:

$$
\theta_{c, t}^{T}=\theta_{c, t-1}^{T}+\theta_{c, t}^{1} 1\left\{A_{t}^{1}>5\right\}+\theta_{c, t}^{1} 1\left\{A_{t}^{2}>5\right\}
$$

The horizon is finite. At period T, assumed to be 45 years of age, the woman faces a terminal value function that depends on the state space. I assume:

$$
V_{T+1}=A_{c} \theta_{c, t}^{T}+A_{e} X_{f, T+1}
$$

where $A_{c}$ and $A_{e}$ are parameters to be estimated.

\section{Unobserved Heterogeneity}

Finally, the distribution of unobserved heterogeneity is $f(\omega)$ where I assume that $f(\cdot)$ follows a discrete distribution with $\mathrm{K}$ support points. The support points are sometimes called "types." This treatment of unobserved heterogeneity follows Heckman and Singer (1984). Recall that there is unobserved heterogeneity over income, wages, home quality and cognitive skills. Because the unobserved heterogeneity also determines the initial conditions through a process not modeled

here, I allow the probability of being a particular type to be a function of the initial conditions. In the estimation, I assume that there are $\mathrm{K}=2$ types.

\section{Solution Method}

The model is solved backward from the last period. Given the state space, I draw from the distribution of shocks and calculate the optimal choice. I repeat this process and take the average over the optimal values. This simulated integration gives the expected maximum value at that particular state space point. I 
then pick a different state space point and repeat the simulated integration. The resulting function is known in the literature as the EMAX function. Instead of calculating the EMAX at every point in the state space, I use an approximation method developed by Keane and Wolpin (2004). First, I randomly select a subset of the state space points and calculate the EMAX at each point in the randomly drawn subset. Second, I use a polynomial approximation to the EMAX function and use the predicted value to "fill-in" any state space point where I did not calculate the EMAX. For the evolution of marriage and number of children, I use exact integration because I have assumed a closed form for the probabilities. 


\section{Chapter 4}

\section{Measuring Child Care and Home Quality}

The quality of an environment, either in the home or in a child care setting, is intended to capture the amount of stimulation that children receive in that environment. ${ }^{14}$ Stimulation can come in the form of developmentally appropriate materials, whether the caregiver encourages the child and the kinds of activities that the classroom or child does during their time in child care, such as reading books or singing songs. ${ }^{15}$ In the child care literature, researchers make a distinction between structural and process measures of quality. ${ }^{16}$ Structural measures include the student-caregiver ratio and the qualifications of the caregiver. Improved structural measures are thought to increase the likely of high quality care but do not guarantee improved care quality. On the other hand, process measures capture what actually occurs in the child care environment and are the actual "quality" of the child care environment.

One commonly used measure of child care quality is the Early Childhood Environment Rating Scale (ECERS). The ECERS asks questions about the routines that occur in the classroom, the use of language by the caregiver toward the child, whether there is time for motor activities, whether the child engages in

\footnotetext{
${ }^{14}$ The word quality is typically used in reference to child care settings. The quality of home environment might be called the HOME score (in refernence to a particular scale) or home inputs. I use quality to define the amount of measured stimulation in any environment whether home or child care. The point of my paper is that the foregone alternative of making a child care choice is often the quality of the home environment.

${ }^{15}$ See Love et al. (2006), Caldwell and Bradley (1984) for discussions and definitions.

${ }^{16}$ See Vandell and Wolfe (2000).
} 
creative activities such as music or art, observer impressions of the "tone of interaction" and many others. Other scales, such as the Global Rating Scale, attempt to measure whether the relationship between the care provider and the child is "positive" by assessing how the caregiver speaks to the child, whether they enjoy the child, etc. ${ }^{17}$ Although the scales have some overlap, there does not seem to be complete uniformity in questions that related to quality. In general, measures of child care "quality" can then be any variable that measures materials in the care environment and whether the interactions between child and caregivers are "stimulating."

Analogous to issue of measuring child care quality is the issue of measuring home quality. A commonly used measure is the Home Observation for the Measurement of the Environment (HOME). The HOME scale is based on direct observation and interviewer questions of the parent. The questions vary by the age of the child. Some subscales that span multiple ages are questions related to the learning environment, parental responsivity, and learning materials. ${ }^{18}$ The HOME scale includes questions about whether the parent spontaneously spoke to the child, verbal responses to the child, whether the parent provided toys to the child and whether the interviewer felt the play environment was safe. The goal is capture whether the child lives in a stimulating environment both from the mother and from items that the family might buy. ${ }^{19}$ Bradley and Caldwell (1984) argue that the HOME scale is consistent with "Piagetian notions about

\footnotetext{
${ }^{17}$ Lamb (1998) has a discussion of child care quality with examples of difference scales that measure quality and the different areas that the scales measure.

${ }^{18}$ See the Home Observation for Measurement of the Environment (HOME) Inventory.

${ }^{19}$ Bernal and Keane (2008) make a distinction between time and goods inputs, which I do not follow. Todd and Wolpin (2007) also discuss how the HOME scale conflates time and goods inputs and also combines items that could logically be considered inputs with items that instead seem to be proxies for inputs. Instead my approach is closer to Cunha and Heckman (2008), who model the inputs into the production function as a latent variable.
} 
the development of sensorimotor and preoperational thinking."

An advantage of using the ECERS and HOME scales is that these scales have both been extensively used and validated in the literature. A disadvantage is the weighting of the scale items is essentially arbitrary. Cunha and Heckman (2008) state "[t]he constructed indices often have an ad hoc quality about them and may be poor proxies for the true combination of inputs that enter the technology." In my data, I have measures from the HOME scale and from the ECERS scale. However, a limitation is the data contain only a subset of questions from the HOME scale and the ECERS was collected only for a small subset of children. The data also contain additional questions that could be considered inputs and I risk losing information by focusing only on the HOME and ECERS scale. Table 2 have a list of information in the data that I use to form the measure of the home environment and table 3 has a comparable list of questions that I use the form the child care quality measure. The home quality measures are a mix of direct observation and self-reports by the parents. The child care quality measures are reported by the child care providers. Similar to the existing scales, I choose to combine all of the information on inputs into a single variable for the home environment and a single variable for the child care environment. Specifically, for the measurements of home and child care quality and for each round, I use principle components analysis (PCA) to collapse the data into an index and I treat the predicted component as data, where the component is chosen to explain the maximize amount of variance in the measures of home and child care quality. Although using PCA does not address the criticism that the weights are arbitrary, PCA captures a component that explains the maximum amount of variance in the data and allows me to expand my sample and to incorporate all input information in the data. Moreover, given that questions vary across 
existing scales, it seems that there is no consensus on which measures should be used to capture the quality of children's experiences. ${ }^{20}$

\section{Chapter 5}

\section{Data}

I estimate the model using data from the Early Childhood Longitudinal Study - Birth Cohort (ECLS-B). The ECLS-B is a nationally representative panel of 14,000 children born in 2001. Researchers followed the children from birth until kindergarten entry and collected detailed information about their family background, home environment, maternal work decisions, maternal wages, family income, child care usage and cognitive achievement outcomes. Child care providers were given questionnaires that asked detailed information about the care environment, care activities, qualifications and questions designed to elicit information about their attitudes towards child care. Families were also asked questions about the kinds of activities the child engaged in and the materials and toys the child had access to. Selected summary statistics for the data used in the analysis is given in table 1. The measures used in the principal-components analysis for the child care and home environment quality are given in tables 2 and 3.

The ECLS-B consists of five rounds of data collection. The researchers visited the children when they were approximately 9 months, 2 years, 4 years and 5 years with a follow-up round for delayed kindergarten entrants. I use the first four

\footnotetext{
${ }^{20}$ See Layzer and Goodson (2006) for a discussion about the difficulties in defining and measuring child care quality and relating child care quality to child outcomes.
} 
rounds. ${ }^{21}$ Two issues complicate taking the model to the data. First, the spacing between rounds is irregular. Second, there is a large amount of variability in assessment age at each round. For example, in the 9 month round, the children actually ranged in age from 6 months to 18 months. Because of these features of the data set, I instead organize the data into 6 month bins with bins at 6 12 months, 12 - 18 months, 18 - 24 months, etc. For each round I will see some children in each age bin and I will see each child four times (ignoring attrition). I treat the observations between rounds when I do not see the child as missing data. Because the amount of missing data is large, I do not estimate the model by maximum likelihood. Instead I use the method of simulated moments where I simulate different paths and form statistics for the children when I observe them. The estimation procedure is described in more detail below.

For the cognitive achievement measures, the ECLS-B contains the Bayley Short Form- Research Edition (BSF-R) at the 9 month and 2 year waves. The BSF-R uses a subset of the Bayley Scales for Infant Development, 2nd Edition (BSID-II), which is a assessment that places infants in various situations and scores their responses. The BSF-R can be given to children from 2 to 30 months. The assessment contains both a mental and a motor score. I use the mental score for my analysis. Examples situations from the BSF-R include ringing bells and checking whether the child turns their head in response and whether the child vocalizes at least once during the interview. Each situation contains a series of activities that are age and developmentally appropriate. The assessor checks the child's responses in order to locate their basal and ceiling levels. For the ECLS$\mathrm{B}$, the interviewers gave children a core assessment and moved downward to the

\footnotetext{
${ }^{21}$ The fifth round of data collection is for the subset of children who are delayed kindergarten entrants.
} 
basal set for children for whom the core set was too difficult. The ceiling set was used for children who got the core set perfectly. Instead of reporting the BSF-R score, researchers used Item Response Theory (IRT) to predict a scale score on the BSID-II, which is what is reported in the data file. The data also contain a norm referenced T-score.

For cognitive achievement at older ages, the ECLS-B administered math and early reading tests. The math and reading tests were adaptive tests derived from well-known early childhood assessments. To encourage cross-study comparisons, the ECLS-B used questions previously developed for the ECLS-K, the Head Start Impact Study and the Family and Child Experiences Study. In addition, questions were added from the Peabody Picture Vocabulary Test (PPVT, various forms), the Test of Early Mathematics Ability-3 (TEMA-3), the Preschool Comprehensive Test of Phonological and Print Processing (Pre-CTOPPP) and the PreLAS 2000. ${ }^{22}$ Again, the ECLS-B contain scale scores and T-scores for both the math and early reading tests. I use the scale scores. To combine information, I simply average the math and early reading scores. Finally, because test scores do not have a metric, I standardize the scale scores by age.

\footnotetext{
${ }^{22}$ For additional information on the cogntive assessments see "The ECLS-B Direct Assessment Choosing the Appropriate Score for Analysis."
} 


\section{Chapter 6}

\section{Estimation}

The model has 73 parameters that I estimate using the method of simulated moments. The basic idea is to match statistics from simulated data generated from the model to corresponding statistics in the data. The procedure works as follows. Given a set of parameters, I solve the model by iterating backward from the terminal value. I then use each woman's initial conditions to draw her type from the discrete distribution of types. Given the model solution, her type and the initial conditions, I then simulate a path of endogenous variables for each woman in the data set. I repeat this procedure five times to create five "clones"

of each person in the data set. I calculate statistics from the simulated data using only the rounds where I actually observe the families. The estimation procedure iterates between the model solution and objective function, which is a weighted distance between statistics computed from the data and corresponding statistics computed from the simulated data. I weight the moment difference by the inverse of the variance of each data moment.

There are two complications in the estimation. The first estimation issue is that the model has multiple children per family but I only observe one child per family in the ECLS-B . It is important to consider multiple children in the estimation because restricting the sample to families with one realized child could bias the estimation if families perceive that they will have more children even if they actually do not end up having more children. I am able to identify the 
model with multiple children through assumptions about the mother's utility over cognitive skills and through the estimation procedure. I assume that the children's skills enter linearly and additively separably in the utility function so that mothers care about efficiency when making decisions. ${ }^{23}$ Then because I use unconditional simulations from the initial conditions, I never have to calculate conditional choice probabilities for unobserved state space elements such as the cognitive skills of other children in the family. Although my assumptions about the mother's utility function is not testable because I never observe the cognitive skills of other children in family, the model does have implications for how sibling's cognitive achievement scores are correlated. ${ }^{24}$ In the estimation results section I present simulated evidence from the model about the intra-sibling correlation in cognitive skills and birth order effects on cognitive achievement, which I compare to other studies to give an idea about the model's predictions. I also plan to explore the robustness of my conclusions in future work by using a CES aggregator of the children's cognitive skills for different assumptions about the value of the complementary parameter.

The second estimation issue is that the ECLS-B is not a random sample of children but a sample of children born in 2001. However, I assume that the model begins when the mother first has a child, which could be in or before 2001. In order for the mother to be selected in the ECLS-B, she must have a sequence of shocks such that she has a birth in 2001. I mimic the ECLS-B sample selection procedure by only keeping sequences of shocks with a birth in 2001 .

\footnotetext{
${ }^{23}$ Even when multiple children are observed estimates of the efficiency vs. equity trade-offs have produced different results. See the discussion and papers cited in Behrman (1997).

${ }^{24}$ The ECLS-B does have information on twins, which I do not use in the estimation, but this could be another potential avenue to check the modeling assumptions.
} 


\section{Objective Function}

Suppose $\theta$ is the vector of parameters to estimate. Let $K_{i}$ be an $\mathrm{M}$ x 1 vector function of the data for family i. The method of simulated moments estimator is given by:

$$
\hat{\theta}_{m s m}=\underset{\theta}{\operatorname{argmin}} \psi(\theta)
$$

with:

$$
\begin{aligned}
& \psi(\theta)= \\
& {\left[\frac{1}{N} \sum_{i=1}^{N}\left[K_{i}-\frac{1}{S} \sum_{s=1}^{S} k_{i}\left(u_{i}^{s} ; \theta, \omega_{i}^{s} \mid u_{i}^{s} \in \mathrm{ECLSB}\right)\right]\right] W^{-1}} \\
& {\left[\frac{1}{N} \sum_{i=1}^{N}\left[K_{i}-\frac{1}{S} \sum_{s=1}^{S} k_{i}\left(u_{i}^{s} ; \theta, \omega_{i}^{s} \mid u_{i}^{s} \in \mathrm{ECLSB}\right)\right]\right]}
\end{aligned}
$$

$K_{i}: \mathrm{M} \times 1$ vector function of the data for family i

$k_{i}\left(u_{i}^{s} ; \theta, \omega_{i}^{s}\right): \mathrm{M} \mathrm{x} 1$ vector function of the simulated data for

family i given draw $u_{i}^{s}$ and permanent component $\omega_{i}^{s}$

$W^{-1}$ : weighting matrix

The simulated integration over the shocks $u_{i}^{s}$ also includes integrating out the unobserved heterogeneity $\omega_{i}^{s}$, which I draw from the discrete distribution given family i's initial conditions. The conditioning statement $u_{i}^{s} \in$ ECLSB captures that the sequence of shocks must be such that the mother has a birth in 2001 in order to have been selected into the ECLS-B. For the weighting matrix W, I use 
the inverse of the diagonal variance matrix of the data moments.

\section{Standard Errors}

To simplify notation let $\mu(\theta)=\frac{1}{S} \sum_{s=1}^{S} k_{i}\left(u_{i}^{s} ; \theta, \omega_{i}^{s} \mid u_{i}^{s} \in\right.$ ECLSB) be the vector of simulated moments given the parameter vector $\theta$. Taking the derivative of the objective function with respect to $\theta$ yields the following first order conditions:

$$
\left.\frac{\partial \mu}{\partial \theta}\right|_{\hat{\theta}_{N}} ^{\prime} W^{-1}\left[\frac{1}{N} \sum_{i=1}^{N}\left[K_{i}-\mu\left(\theta_{N}\right)\right]=0\right.
$$

A Taylor expansion around $\mu\left(\theta_{0}\right)$ gives:

$$
\mu\left(\theta_{N}\right)=\mu\left(\theta_{0}\right)+\left.\frac{\partial \mu}{\partial \theta}\right|_{\theta_{*}}\left(\theta_{N}-\theta_{0}\right)
$$

for some $\theta_{*}$ between $\theta_{0}$ and $\theta_{N}$. Plugging the Taylor expansion into the first order condition, premultiplying and rearranging gives:

$$
\sqrt{N}\left(\theta_{N}-\theta_{0}\right)=\left(\left.\left.\frac{\partial \mu}{\partial \theta}\right|_{\hat{\theta}_{N}} ^{\prime} W^{-1} \frac{\partial \mu}{\partial \theta}\right|_{\theta_{*}}\right)^{-1}\left(\left.\frac{\partial \mu}{\partial \theta}\right|_{\hat{\theta}_{N}} ^{\prime} W^{-1}\left[\frac{1}{\sqrt{N}} \sum_{i=1}^{N}\left[K_{i}-\mu\left(\theta_{0}\right)\right]\right)\right.
$$

Applying a Central Limit Theorem gives the following variance-covariance matrix for the limiting distribution:

$$
\left(\left.\left.\frac{\partial \mu}{\partial \theta}\right|_{\hat{\theta}_{N}} ^{\prime} W^{-1} \frac{\partial \mu}{\partial \theta}\right|_{\theta_{*}}\right)^{-1}\left(\left.\left.\frac{\partial \mu}{\partial \theta}\right|_{\hat{\theta}_{N}} ^{\prime} W^{-1} V\left[K-\mu\left(\theta_{0}\right)\right] W^{-1} \frac{\partial \mu}{\partial \theta}\right|_{\hat{\theta}_{N}}\right)\left(\left.\left.\frac{\partial \mu}{\partial \theta}\right|_{\hat{\theta}_{N}} ^{\prime} W^{-1} \frac{\partial \mu}{\partial \theta}\right|_{\theta_{*}}\right)^{-1}
$$

I then approximate $\left.\frac{\partial \mu}{\partial \theta}\right|_{\hat{\theta}_{N}}$ using the matrix of numerical partial derivatives calculated at the optimal parameter value and $V\left[K-\mu\left(\theta_{0}\right)\right]$ is approximated by the variance-covariance of the moments at the optimal parameter value. 


\section{Moments}

I use 622 moments in the estimation. The moments are as follows (number of moments in parentheses):

- Average child cognitive skills

1. by mother's marital status (2)

2. by race $(2)$

3. by mother's education (4)

4. by father's education (4)

5. by father's experience (6)

6. by mother's age at first birth (4)

7. by number younger siblings $(2)$

8. by lagged cognitive achievement quartile (4)

9. by lagged hours and quartiles of home and child care quality ()

10. by number older siblings (3)

11. by age of focal child (7)

12. by age of mother (12)

13. by lagged home inputs, child care inputs and hours of care (36)

14. lagged cognitive achievement (4)

15. variance by lagged cognitive achievement (4)

16. standard deviation (1)

- Percent in full-time child care 
1. by parents' marital status (2)

2. by race $(2)$

3. by mother's education (4)

4. by father's education (4)

5. by father's experience (6)

6. by mother's age at first birth (4)

7. by number younger siblings (2)

8. by number older siblings (3)

9. by age of focal child (7)

10. by age of mother (12)

11. standard deviation (1)

- Percent in part-time child care

1. by parents' marital status (2)

2. by race $(2)$

3. by mother's education (4)

4. by father's education (4)

5. by father's experience (6)

6. by mother's age at first birth (4)

7. by number younger siblings (2)

8. by number older siblings (3)

9. by age of focal child (7) 
10. by age of mother (12)

11. standard deviation (1)

- Average child care quality

1. by parents' marital status (2)

2 . by race $(2)$

3. by mother's education (4)

4. by father's education (4)

5. by father's experience (6)

6. by mother's age at first birth (4)

7. by number younger kids (2)

8. by number older kids (3)

9. by age of focal child (5)

10. by age of mother (11)

11. standard deviation (1)

12. autocorrelation between rounds (1)

- Average child care price

1. by marital status (2)

2. by race (2)

3. by mother's education (4)

4. by father's education (4)

5. by father's experience (6) 
6. by mother's age at first birth (4)

7. by number younger kids (2)

8. by number older kids (3)

9. by age of focal child (7)

10. by age of mother (12)

11. standard deviation (1)

12. autocorrelation between rounds (1)

- Percent in Head Start

1. by parents' marital status (2)

2 . by race $(2)$

3. by mother's education (4)

4. by father's education (4)

5. by father's experience (5)

6. by mother's age at first birth (4)

7. by number younger kids (2)

8. by number older kids (3)

9. average Head Start child care quality (1)

10. standard deviation Head Start child care quality (1)

- Average home quality

1. by marital status (2)

2 . by race $(2)$ 
3. by mother's education (4)

4. by father's education (4)

5. by father's experience (6)

6. by mother's age at first birth (4)

7. by number younger kids (2)

8. by number older kids (3)

9. by age of focal child (7)

10. standard deviation (1)

11. autocorrelation between rounds (1)

- Percent in full-time labor force participation

1. by parents' marital status (2)

2. by race $(2)$

3. by mother's education (4)

4. by father's education (4)

5. by father's experience (6)

6. by mother's age at first birth (4)

7. by number younger siblings $(2)$

8. by number older siblings (3)

9. by age of focal child (7)

10. by age of mother (12)

11. standard deviation (1) 
- Percent in part-time labor force participation

1. by parents' marital status (2)

2. by race $(2)$

3. by mother's education (4)

4. by father's education (4)

5. by father's experience (6)

6. by mother's age at first birth (4)

7. by number younger siblings $(2)$

8. by number older siblings (3)

9. by age of focal child (7)

10. by age of mother (12)

11. standard deviation (1)

- Joint distribution of labor supply and child care hours (8)

- Child care transition probabilities between rounds (8)

- Labor supply transition probabilities between rounds (8)

- Average mother's wage:

1. by marital status (2)

2. by race (2)

3. by mother's education (4)

4. by father's education (4)

5. by father's experience (6) 
6. by mother's age at first birth (4)

7. by number younger kids (2)

8. by number older kids (3)

9. by age of focal child (7)

10. by age of mother (12)

11. standard deviation (1)

12. autocorrelation between rounds (1)

- Average husband's income:

1. by race $(2)$

2. by mother's education (4)

3. by father's education (4)

4. by father's experience (6)

5. by mother's age at first birth (4)

6. by number younger kids (2)

7. by number older kids (3)

8. by age of focal child (8)

9. standard deviation (1)

10. autocorrelation between rounds (1)

- Percent married:

1 . by race $(2)$

2. by mother's education (4) 
3. by mother's age at first birth (4)

4. by number younger kids (2)

5. by number older kids (3)

6. by age of focal child (7)

7. by age of mother (12)

8. standard deviation (1)

- Number of children less than 5:

1. by marital status (2)

2. by race $(2)$

3. by mother's education (4)

4. by father's education (4)

5. by father's experience (6)

6. by mother's age at first birth (4)

7. by age of mother (12)

8. standard deviation (1)

- Number of children older than 5:

1. by marital status (2)

2 . by race $(2)$

3. by mother's education (4)

4. by father's education (4)

5. by father's experience (6) 
6. by mother's age at first birth (4)

7. by age of mother (10)

8. standard deviation (1) 


\section{Chapter 7}

\section{Child Care Subsidies}

Child care subsidies are an important policy tool to encourage the labor force participation of poor women by defraying the costs associated with child care (Adams and Rohacek 2002). Blau (2003) provides an extended discussion of the issues related to the design of different child subsidy programs. In particular, Blau (page 445) emphasizes "the trade-off faced by policymakers between the goals of improving child well-being and increasing economic self-sufficiency." Subsidies typically have few restrictions on the type of care for which they can be used and recent research suggests these subsidies may have harmful effects on child outcomes (Herbst and Tekin 2010; Hawkinson, Griffen, Dong and Maynard 2010). An open question is to understand the mechanisms through which child care subsidies affect children's cognitive achievement and to relate the design of child care subsidy policy parameters to both labor supply and cognitive achievement outcomes.

\section{Institutional Details}

Federal funding for child care subsidies is provided by the Child Care Development Fund (CCDF).$^{25}$ In 2006, the total federal funding of the CCDF was almost 5 billion dollars. Part of the federal funding is given automatically. The other

\footnotetext{
${ }^{25}$ All the information in this section is distilled from the House Ways and Means Committee's 2008 Green Book section on child care and the Child Care Bureau's "State Child Care Subsidies: Trends in Rate Ceilings and Family Fees (May 2005)" publication.
} 
part of federal funding is contingent on states matching federal funds with states monies. In addition, states are allowed to transfer up to $30 \%$ of the money from their TANF block grant to the CCDF. For example, in 2006, states contributed an additional 4 billion dollars to the CCDF.

The CCDF targets poor working parents to assist with the expenses related to child care. To be eligible, the federal government stipulates that families be below $85 \%$ of their state's median income level. Beyond this requirement, states have flexibility in designing their programs. The CCDF funding is not an entitlement and states are required to give preference for more economically disadvantaged families. Children must be less than 13 years old and parents must both (if married) be working or in school. In 2007, there were 992,400 families and 1.7 million children served by the CCDF per month. Herbst (2008) summarizes that "these studies suggest that ... the states serve between $15 \%$ and $30 \%$ of the [CCDF] eligible population."

CCDF subsidizes child care by providing recipients with a voucher or certificate that can be used to purchase child care services. ${ }^{26}$ The maximum price per hour that the state will reimburse for child care expenses is referred to as the "rate ceiling." States are required to conduct market surveys of child care costs every two years and per federal recommendation, many states set the rate ceiling at the 75 th percentile of the distribution of market prices. To share costs, parents must pay a co-pay that is either a percentage of their income or, in a few states, a percentage of the rate ceiling. The co-pay varies by family size and across states and, in some states, the copay can be waived for the very poor.

\footnotetext{
${ }^{26}$ Some states give cash reimbursement for child care expenses and some states have child care providers that contract directly with the state to provide child care to CCDF recipients.
} 


\section{Modeling Child Care Subsidies}

The child care subsidy system fits neatly into the model through the budget constraint. First, I define some terms:

$$
\begin{aligned}
& \text { rate ceiling }=r c \\
& \text { copay }=\psi\left(I_{t} M_{t}+w_{t}\left(1000-h_{L, t}\right)\right) \\
& \text { income cutoff }=\overline{\mathrm{I}}^{\mathrm{s}}
\end{aligned}
$$

where $\psi$ is the percentage of income that is a copay. Let $S_{t}$ be 1 if family is subsidy eligible, 0 otherwise:

$$
S_{t}=1\left\{h_{L, t}<1000\right\} 1\left\{I_{t} M_{t}+w_{t}\left(1000-h_{L, t}\right)<\overline{\mathrm{I}}^{\mathrm{s}}\right\}
$$

where $1\left\{h_{L, t}<1000\right\}$ captures that women must work and $1\left\{I_{t} M_{t}+w_{t}(1000-\right.$ $\left.\left.h_{L, t}\right)<\overline{\mathrm{I}}^{\mathrm{s}}\right\}$ indicates that family income must be below $85 \%$ of the state median income. To fit the child care subsidy program into the budget constraint, recall the price of child care is $p_{c c}$. If the price is less than the rate ceiling, the family pays only the copay. If the price is greater than the rate ceiling, then the family pays the copay plus the difference between the rate ceiling and the price for every hour of child care. ${ }^{27}$ For exposition I ignore Head Start and multiple children.

\footnotetext{
${ }^{27}$ There is a second type of subsidy scheme where the state will not pay for child care that costs more than the rate ceiling. This is a trivial extension of the current analysis but I will add it for future work.
} 
Under a subsidy, the mother would have the following budget constraint:

$$
\begin{aligned}
& C_{t}+p_{c c, t} h_{c c, t}\left(1-S_{t}\right)+ \\
& {\left[0 h_{c c, t} 1\left(p_{c c, t} \leq r c\right)+1\left(p_{c c, t}>r c\right)\left[p_{c c, t}-r c\right] h_{c c, t}+\psi\left(I_{t} M_{t}+w_{t}\left(1000-h_{L, t}\right)\right)\right] S_{t}} \\
& =\tau I_{t} M_{t}+w_{t}\left(1000-h_{L, t}\right)
\end{aligned}
$$

The mother will choose to not use the subsidy if the total cost of child care under the subsidy exceeds the cost without the subsidy. This can occur if the price is so low that the copay is greater than the reduction in the price per hour. To check the participation constraint, I simply compare costs and set the subsidy eligibility variable equal to zero in the case that the mother would not use the subsidy:

$$
\begin{aligned}
& 0 h_{c c, t} 1\left(p_{c c, t} \leq r c\right)+1\left(p_{c c, t}>r c\right)\left[p_{c c, t}-r c\right] h_{c c, t}+\psi\left(I_{t} M_{t}+w_{t}\left(1000-h_{L, t}\right)\right) \\
& \leq p_{c c, t} h_{c c, t}
\end{aligned}
$$

An important caveat to modeling the child care subsidy program that limits my analysis is that I cannot explicitly incorporate state level variation in the subsidy policy parameters because of computational considerations. For example, families living in different states (and counties) face different rate ceilings, different income eligibility cutoffs and different copays. I sidestep these issues by dropping subsidy recipients from the estimation and by calibrating the policy parameters to national averages. Using information from the National Center for Child Poverty (NCCP), I set the biannual income cutoff to $\$ 15,500$, the copay to $9 \%$ of family income and $\$ 3.89$ for the rate ceiling. ${ }^{28}$ In the counterfactual simu-

\footnotetext{
${ }^{28}$ See the 50 -State Policy Wizard for CCDF subsidies at the NCCP website.
} 
lations, I use the calibrated program parameters as a baseline and I explore how changing features of the subsidy programs affects both labor force participation and the cognitive skills of children through decisions about child care use and quality decisions. 


\section{Chapter 8}

\section{Estimation Results}

\section{Parameters Estimates}

The parameter estimates and associated standard errors are displayed in Table C.1 in Appendix C. The parameters of the cognitive achievement production function play an important role in tracing out the impact of different policy counterfactuals on the cognitive skills of children. The parameters suggest that cognitive skills are persistent $\left(\gamma_{1, c}=0.79\right)$, a child's environment is an important determinant of skills $\left(\gamma_{3, c}=0.43\right)$ and that home environments are on average more productive than child care environments in producing cognitive skills $(\alpha=0.59)$. These parameter estimates are important for the counterfactuals because the persistence in the production of cognitive skills causes inputs in one period to affect future cognitive achievement through the value-added achievement production function.

Besides these parameters, the type distribution parameter on being black is insignificant although being black is significant determinant of wage and income offers. This is an important result because it suggests that observed differences by race in marriage rates, education levels, wage and income offers and their effects on choices can explain the black-white achievement gap. ${ }^{29}$ Other parameters have intuitive and obvious signs and magnitudes.

\footnotetext{
${ }^{29}$ This is consistent with Fryer and Levitt (2004) who document that the black-white achievement gap at kindergarten entry in the ECLS-K shrinks dramatically with a few controls.
} 
Some of the features of the estimates are difficult to understand without simulating the model. In Table C.2, I compute wage elasticities, intra-sibling correlation in cognitive skills and birth order effects on cognitive skills. Computing the elasticities on data simulated from the model at the final parameter estimates, the intensive labor supply elasticity is 0.89 and the extensive labor supply elasticity is 0.88 , which are consistent with previously high estimated wage elasticities for women. ${ }^{30}$ Comparing cognitive skills among siblings, I find 0.48 for the intrasibling correlation in cogntive achievement test scores, which is very close to the 0.5 intra-sibling correlation for IQ scores among siblings reported in Scarr (1994).

I find evidence for both spurious and genuine birth order effects in the simulated data. In Table C.2, without conditioning on the number of children, the results show that later born children have lower cognitive achievement test scores on average, which is consistent with reported findings on birth order. However, conditioning on the number of children, the effect of birth order on cognitive achievement diminishes, which is consistent with the theory that mothers with larger families have lower observed or unobserved determinants of their children's cognitive achievement. ${ }^{31}$ However, even conditioning on number of children, the later born children still have lower scores on average. These birth order effects could result from the budget constraint if mothers choose lower and more affordable child care quality. Or, when the number of children increases, low quality home environment mothers could select to be stay at home and not use child care, which would result in a higher dose of low quality home care for later born children.

\footnotetext{
${ }^{30}$ Heckman and McCurdy (1980), Keane and Wolpin (2006).

${ }^{31}$ Rodgers et al. (2000) discuss how most birth order studies use cross-sectional data and that the findings disappear with controls for family size.
} 


\section{Model Fit}

The model fit is displayed in Tables C.3 - C.12 in Appendix C. The model captures well all the main features of the data (Table C.3). There are gaps in cognitive achievement test scores by race, mother's marital status and maternal education (Table C.4). Home quality is higher on average for white children with married parents and mothers with higher education (Table C.9). Child care quality also displays the patterns observed in the data with blacks and children of single parents having, on average, better child care experiences than white children and children with married parents (Table C.6). This reflects the role of Head Start and the higher likelihood of more disadvantaged children being eligible for Head Start. The lower home quality of these groups also increases the marginal productivity of child care quality, which provides an additional incentive for them to accept higher quality child care draws. On the other hand, the lower wages draws of single and black mothers mitigates their ability to pay for child care quality.

The model also captures the U-shape for child care quality as maternal education increases. To the extent that maternal education proxies for socioeconomic status, the child care quality experiences for middle-income children are often the worst because their families are not poor enough to quality for subsidized care but higher quality care is more expensive. Another interesting feature is that quality does not increase dramatically for higher education mothers, which is strange given the apparent productivity of higher quality care. ${ }^{32}$ Such a pattern could reflect poor consumer knowledge of the quality of child care experiences

\footnotetext{
${ }^{32}$ Hagy and Blau (1998) document a similar pattern for the demand for structural measures of quality. Their result is perhaps not as surprising given the lack of productivity of structural measures of quality (Blau 1999) and the weak relation between structural measures and process measures (Blau 1997).
} 
(Walker, 1991) or perhaps the mothers have limited knowledge of the cognitive achievement production function. ${ }^{33}$ The model also picks up the patterns of child care use with small differences in black/white and married/single usage patterns. White mothers have higher wage offers (as a result of higher education and experience), which increases their likelihood to work, but they also are more likely to be married, which increases their demand for leisure through non-labor (husband's) income effects. The higher home quality of married/white mothers gives an additional incentive to stay home because of higher productivity of their inputs in creating cognitive skills. The model also captures different labor force patterns by maternal characteristics (Table C.10), the distribution of decision (Table C.11) and the transition of work and child care decisions (Table C.11).

In Figure F.4, F.5 and F.6, I document several patterns that the model captures even though these moments were not used explicitly in the estimation. It is noteworthy that the model can capture these patterns because it suggests that the within sample fit for some important moments not used in the estimation is reasonable. First, Figures F.4 and F.5 show the emergence of the test score gap by maternal education and by race. The model captures the small initial gaps in test scores by race and maternal education that open up early and persist as the children age. ${ }^{34}$ Second, Figure F.6 plots the average child care quality by race and child's age. Although the data are noisy, the interesting feature of this pattern is that the higher average child care quality for black children occurs only after around age 3. The model captures through the availability of Head Start when the children turn age 3. Black children are disproportionately eligible for

\footnotetext{
${ }^{33}$ Bernal (2008) discusses the assumption that the mothers know the functional form for the production of cognitive achievement.

${ }^{34}$ Fryer and Levitt (2006) also document the small test score gap at the 9 month round in the ECLS-B.
} 
Head Start because of lower average family income so that beginning at age 3 their mothers receive higher average child care quality offers, which pushes up the average child care quality for blacks and the model generates a similar pattern to that observed in the data. 


\section{Chapter 9}

\section{Counterfactuals}

The main goal of the paper is to evaluate the role of two kinds of child care policies, Head Start and child care subsidies, and their effects on (a) children's cognitive achievement and (b) maternal labor force participation. For cognitive skills, I discuss how different policies affect the amount of child care used and the quality of child care chosen. I also document the per capita and total cost associated with different interventions and the effect of policies on closing gaps in cognitive achievement by race.

\section{Head Start}

The results from the Head Start counterfactuals are displayed in Tables D.1 to D.3 in Appendix D. As a model validation exercise, I first use the model to evaluate Head Start using the same design as the Head Start Impact Study (HSIS), a randomized controlled trial of Head Start. The HSIS consisted of two interventions; a group of 4 year olds who were randomized to receive Head Start or not (HSIS 4 year olds) and a group of 3 year olds who were randomized into a treatment group and a delayed treatment control group that could apply again for Head Start at age 4 (HSIS 3 year olds). In Table D.1, I report the effect sizes for two arms of the HSIS computed in my estimated model and from the report of the HSIS. ${ }^{35}$ I report two kinds of estimates of the program's effect. The

\footnotetext{
${ }^{35}$ The effect sizes from the HSIS were computed as follows: for the reading domain outcomes, I averaged across the effect sizes for all of the reading outcomes. For the math domain, I averaged
} 
first, the Intent to Treat estimate, is the average change in the outcome for all eligibles. The second estimate is the Treatment on the Treated, which is the average change in the outcome only for children that use the program.

The intent to treat estimate for the HSIS 4 year olds design is 0.06 in my model and 0.12 in the HSIS study. For the same design, the Treatment on the Treated estimate is 0.12 in my simulations and 0.17 in the HSIS. Using the HSIS 3 year olds design, I find an effect size of 0.07 in my simulations and the HSIS reports 0.05 for the Intent to Treat estimate. The Treatment on the Treated estimate is 0.13 versus 0.06 in the HSIS. Although the HSIS was conducted on a different cohort of children, with a sample of oversubscribed Head Start centers and could not prevent treatment crossovers to other Head Start centers, the effect sizes simulated in my model and reported in HSIS are of a similar magnitude, which provides evidence of the validity of my model. ${ }^{36}$

I next use the model to consider three types policies: removing Head Start completely (an arm that the HSIS did not evaluate), replacing Head Start with cash transfers to eligible families and expanding Head Start services to current non-eligibles. Table D.2 displays the results from these counterfactual experiments. I report Intent to Treat estimates for the effect of the different interventions on Head Start eligibles, where Head Start eligibility can change depending on the income cutoff. The first row illustrates that removing Head Start lowers

across the effect sizes for all of the math outcomes. I then averaged the separate math and reading effect sizes, which most closely approximates my treatment of the data in the ECLS-B. The Treatment on the Treated impacts were derived from the Intent to Treat impacts in the HSIS using the Bloom adjustment.

${ }^{36}$ Todd and Wolpin (2006) use experimental data to validate a structurally estimated economic model. They estimate their model using data from from an experimental evaluation of PROGRESA, a conditional cash transfer program in Mexico. They limit their estimation sample to data in the control group and use the estimated model to predict the experimental impacts of PROGRESA. The difference in my case is that I estimate the model using a completely different data set and only mimic the design of the experiment for the model validation. However, the spirit of the exercise is the same. 
cognitive achievement scores by -0.15 standard deviations at kindergarten entry. Removing Head Start has only a moderate impact on changing maternal labor force participation. This is not surprising given that Head Start imposes no work requirement as a condition of participation. The second row considers the effect of not only removing Head Start but giving Head Start eligible families a cash transfer of the per student spending on Head Start per six months $(\$ 3,610)$. The idea is to test whether in kind transfers are a better method of achieving the aims of Head Start through parents making better decisions when provided the money directly. The results indicate that, compared to providing Head Start, providing transfers lowers cognitive achievement scores (-0.13 SD). The cash transfer also has a large negative effect on maternal labor supply (-10 percentage points) so to the extent that maternal labor supply is a policy objective these unconditional transfers do not encourage labor supply.

Table D.2 rows 3 to 6 gradually expand Head Start by increasing the Head Start income eligibility cutoff. The Intent to Treat estimates increases monotonically in the income cutoff for a maximum of 0.21 SD impact on cognitive achievement at kindergarten entry. This finding suggests that even for higher income children there substantial gains to be had in their cognitive achievement scores at kindergarten entry. ${ }^{37}$ One reason for this is that children from higher income families tend to spend more time in child care and the child care quality data presented in the data section show that child care quality experiences of these children are not particularly high. Providing a relatively higher quality Head Start option increases the cognitive skills of non-eligibles because of their extensive use of low quality child care.

Finally, in Table D.3, I consider the effect of the previously described coun-

\footnotetext{
${ }^{37}$ This result is consistent with Gormley et al., 2005.
} 
terfactuals on closing the black-white (BW) achievement gap. The first column shows that without Head Start the BW achievement gap would be $9 \%$ larger at kindergarten entry. Head Start has a fairly substantial effect of narrowing the BW achievement gap. This finding reflects both the relative productivity of Head Start compared to other forms of child care and the differential access to Head Start by black children, because of family income eligibility cutoffs. The cash transfer in place of Head Start increases the black-white achievement gap; the gap would be $3.96 \%$ higher with cash transfers in place of Head Start. Increasing the eligibility cutoff at first lowers the gap but gradually increases the gap as more and more higher income children benefit from Head Start services. With universal Head Start, the BW achievement gap would actually be $12.11 \%$ larger. This result shows that closing the BW achievement gap can be a paradoxical goal; there are policies that benefit all children yet would increase differences between blacks and whites at kindergarten entry.

\section{Child Care Subsidies}

The results from the child care subsidies counterfactuals are presented in Tables D.4 to D.6 in Appendix D. As discussed previously, I estimate the model without the child care subsidy program and then introduce the program into the model with the policy parameters calibrated to national averages. In Table D.4, I report the effect on cognitive achievement of the calibrated subsidy program; I find that 6 months of exposure increases cognitive achievement scores by 0.034 standard deviations. The child care subsidies also have a large impact on labor force participation; increasing the labor supply by 18 percentage points. ${ }^{38}$ Another

\footnotetext{
${ }^{38}$ This is consistent with the effect of child care costs on maternal employment estimated in Blau and Robins (1988), Connelly (1992) and Ribar (1992).
} 
interesting feature of the simulations is that the subsidy take-up, defined as the percentage of eligible families that use the subsidy, is 40.8 percent, which implies that a substantial fraction of the low take-up of subsidies can be explained by the labor supply decisions of mothers and not using the subsidies for low price child care providers.

I next vary each subsidy policy parameter holding the other two policy parameters constant at their calibrated values. The idea is to describe how changing the policy parameter affects the cognitive skills of children, the labor supply of mothers, the program coverage and the cost per child. In the first block in Table D.4, I gradually increase the copay from 0 percent to 30 percent. The Intent to Treat estimated effect on cognitive skills gradually falls. Although child care quality could increase as the copay increases (by discouraging subsidy recipients from accepting low price child care offers), the effect on cognitive skills seems to diminish. This result is partly driven by lower take-up of the subsidy as the copay increases (falling from $62.9 \%$ to $10.4 \%$ ). The cost per child falls and the total cost of the child care subsidy program (relative to the simulated cost of the baseline child care subsidy program) also falls from 1.87 to 0.11 times the total cost of the baseline program. The total cost subtracts out the copayments from the families so the decrease in total cost is driven both by less program participation and by offsetting receipts from higher parental copayments.

Increasing the rate ceiling from $\$ 0$ to $\$ 20$ while holding the other parameters constant, both the intent to treat parameter on cognitive skills and maternal labor force participation increase as the rate ceiling increases. Cognitive skills increase because more children participate and because mothers can accept higher price/quality child care offers, which also increases the impact on cognitive achievement. Labor force participation increases because the size of the transfer 
increases. However, at a rate ceiling of $\$ 20$, both the cost per child, $\$ 9,223$, and the total relative cost of the program, 3.7 times the baseline subsidy program, increase substantially.

Finally, I vary the income cutoff from $\$ 5,000$ to $\$ 30,000$ and the intent to treat on cognitive achievement falls as the income cutoff increases. Higher income families use the subsidy but the mothers were likely already working and using child care so the child's cognitive skills do not change, which causes the intent to treat parameter to decrease. The final row of Table D.6 examines the effect of a targeted program to very poor mothers (household income less than $\$ 10,000$ per year) and offers a subsidy with a generous rate ceiling ( $\$ 20 /$ hour) and $0 \%$ copay. The results show that this targeted intervention both increases cognitive achievement scores $(0.144 \mathrm{SD})$ and maternal labor supply (0.36 percentage points). Especially for the very poor there do not appear to be trade-offs between encouraging maternal labor supply and improving cognitive achievement.

In Table D.5, I explore more in depth how subsidy policy parameters change the quality of care chosen. The columns supertitled eligibles show the difference in average child care quality between subsidy users and non-users. For example, in the program calibrated to national averages, subsidy users had average quality of 0.06 SD and eligible non-users had average quality of -.02 SD. However, the $\Delta$ Quality column reports that the change in quality is 0 for the subsidy program, which means that the children who are induced to enter child care by the subsidy have no better or worse child care quality experiences than average. The subsidy generates the differences in quality because low-price/low-quality child care users opt not to use the subsidy and high-price/high-quality child care users elect to use the subsidy. The subsidy basically segments the mothers into users and nonusers by the price of child care they would have used anyways. The subsidy is 
capable of improving cognitive achievement primarily by encouraging mothers with low quality home environment to use child care so that their children spend less time at home. In this model, the conclusion is that to improve cognitive achievement the subsidies should be targeted toward children with low quality home environments but that the ability to design the subsidies to improve child care quality experiences is limited.

In Table D.6, I examine the effect of child care subsidies on the black-white (BW) achievement gap. Unlike the Head Start example, I consider the impact on the BW achievement gap average across all periods. The estimated impact is the ability of a particular configuration of policy parameters to decrease (or increase) the achievement gap. The first result is that the child care subsidy program has a very small impact on the BW achievement gap; increasing the gap by 0.4 percent. I then vary the copay, the rate ceiling and the income cutoffs. The effects are generally small and range from positive to negative depending on whether the parameter configuration induces changes more from black or white mothers. The child care subsidy program targeted to mothers with less than $\$ 10,000$ annual income decreases the achievement gap by 1.4 percent. The effect on cognitive skills for this intervention is large and evidently primarily benefits black children but the coverage is low so the effect on the black-white gap is relatively small. 


\section{Chapter 10}

\section{Conclusions}

In this paper, I explore the effects of two kinds of child care policies, Head Start and child care price subsidies, on the cognitive achievement of children and maternal labor supply. I first use the estimated model to examine the effects of the existing Head Start program on participants. I find that Head Start is effective at increasing cognitive achievement (0.15 SD) and when I mimic the design of a randomized evaluation of Head Start I find similar sized impacts. Replacing Head Start with cash transfers has a sizable negative impact on cognitive achievement (-0.13 SD). Expanding Head Start services increases cognitive achievement at kindergarten entry (0.21 SD for a universal program), primarily because many non-eligible children spend significant amounts of time in low quality child care.

Child care subsidies, as typically designed, do not have negative impacts on cognitive achievement. Six months of exposure to a child care subsidy program increases cognitive achievement by 0.043 standard deviations. Child care subsidy policy parameters do have an important role in increasing cognitive achievement but the effect comes through which children participate in child care and not through the child care quality choices. A generous child care subsidy program targeted to very poor households (less than $\$ 10,000$ annual income) both increases children's cognitive achievement scores and increases labor force participation of mothers. For the some families, there are no trade-offs between improving cognitive skills and increasing labor force participation. 


\section{Appendix A: Summary Statistics}

Table A.1: Descriptive Statistics

\begin{tabular}{lc}
\hline \hline Child care participation & $47.1 \%$ \\
Labor force participation women & $57.1 \%$ \\
& \\
Average hourly wage $(\$)$ & 21.37 \\
Average income $(\$)$ & 28,350 \\
Average price child care / hour $(\$)$ & 4.93
\end{tabular}

Average number of years of education

Wives

14.37

Husbands

14.46

Average number of years work experience at baseline

Wives

7.01

Husbands

13.07

Age at first birth

27.55

Average number of children

2.04

Percent married

$94.5 \%$

Percent black

$7.4 \%$

Sample size

3,000

Notes: Income is over 6 month for married men only. Marriage includes cohabitation. Sample size rounded to nearest 50 per NCES requirements. 
Table A.2: Home Quality Measurements

\begin{tabular}{|c|c|c|c|c|c|c|c|c|}
\hline & \multicolumn{2}{|c|}{$\begin{array}{l}\text { Round } 1 \\
\mathrm{~N}=4350\end{array}$} & \multicolumn{2}{|c|}{$\begin{array}{l}\text { Round } 2 \\
\mathrm{~N}=3800\end{array}$} & \multicolumn{2}{|c|}{$\begin{array}{l}\text { Round } 3 \\
\mathrm{~N}=4200\end{array}$} & \multicolumn{2}{|c|}{$\begin{array}{l}\text { Round } 4 \\
\mathrm{~N}=3200\end{array}$} \\
\hline & Mean & $\mathrm{SD}$ & Mean & $\mathrm{SD}$ & Mean & $\mathrm{SD}$ & Mean & $\mathrm{SD}$ \\
\hline $\begin{array}{l}\text { Caregiver spoke spontaneously } \\
\text { to child? }{ }^{1}\end{array}$ & 0.94 & 0.25 & 0.98 & 0.15 & . & . & . & . \\
\hline Caregiver responded verbally child? ${ }^{1}$ & 0.86 & 0.34 & 0.97 & 0.17 & . & . & . & . \\
\hline $\begin{array}{l}\text { Caregiver caressed/kissed/hugged } \\
\text { child? }^{1}\end{array}$ & 0.95 & 0.21 & 0.95 & 0.21 & . & . & . & . \\
\hline Caregiver provided toys to child? ${ }^{1}$ & 0.84 & 0.37 & 0.84 & 0.37 & . & . & . & . \\
\hline $\begin{array}{l}\text { Caregiver interfered with } \\
\text { child's actions? }^{1}\end{array}$ & 0.79 & 0.41 & 0.77 & 0.42 & . & . & . & . \\
\hline Caregiver kept child in view? ${ }^{1}$ & 0.98 & 0.15 & 0.95 & 0.21 & . & . & . & . \\
\hline Play environment was safe ${ }^{1}$ & 0.97 & 0.16 & 0.99 & 0.11 & . & 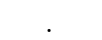 & . & . \\
\hline Read books to child? ${ }^{2}$ & 2.85 & 1.01 & 3.29 & 0.84 & 3.23 & 0.81 & 3.21 & 0.81 \\
\hline Tell stories to child? ${ }^{2}$ & 2.55 & 1.12 & 2.70 & 1.03 & 2.71 & 0.92 & 2.58 & 0.89 \\
\hline Sings songs with child? ${ }^{2}$ & 3.64 & 0.70 & 3.60 & 0.69 & 3.28 & 0.84 & 3.05 & 0.92 \\
\hline Talk about books? ${ }^{2}$ & & & & & . & . & 2.99 & 0.87 \\
\hline Take on errands? ${ }^{2}$ & 3.35 & 0.88 & 3.38 & 0.81 & . & . & . & . \\
\hline Play peek-a-boo? ${ }^{3}$ & 5.00 & 1.14 & . & . & . & . & . & . \\
\hline $\begin{array}{l}\text { Tickle/blow on belly/ } \\
\text { move playfully? }\end{array}$ & 5.78 & 0.58 & . & . & . & . & . & . \\
\hline $\begin{array}{l}\text { Walk/yard/park/ } \\
\text { playground } ?^{3}\end{array}$ & 4.15 & 1.35 & . & . & 3.48 & 0.99 & . & . \\
\hline Number soft toys & . & . & 25.34 & 29.00 & . & . & . & . \\
\hline Number push/pull toys & . & . & 12.54 & 20.52 & . & . & . & . \\
\hline Number books & . & . & 58.68 & 52.25 & 90.32 & 102.25 & 103.55 & 115.67 \\
\hline Number records/tapes/CDs & . & . & 12.85 & 18.96 & . & . & . & . \\
\hline Zoo, aquarium, or petting farm? ${ }^{1}$ & . & . & 0.31 & 0.46 & . & . & . & . \\
\hline $\begin{array}{l}\text { Art gallery, museum, } \\
\text { or historical site? }{ }^{1}\end{array}$ & . & . & 0.15 & 0.36 & . & . & . & . \\
\hline Visited library? ${ }^{1}$ & . & . & 0.31 & 0.46 & 0.43 & 0.50 & 0.46 & 0.50 \\
\hline Play chasing games? ${ }^{3}$ & . & . & 3.77 & 1.04 & . & . & . & . \\
\hline Play with games or toys indoors? ${ }^{3}$ & . & . & 4.35 & 0.84 & . & . & . & . \\
\hline Go to a restaurant or out to eat? ${ }^{3}$ & . & . & 2.18 & 0.76 & . & . & . & . \\
\hline $\begin{array}{l}\text { Affection by hugging, kissing } \\
\text { or holding? }\end{array}$ & . & . & 4.86 & 0.39 & 4.77 & 0.50 & . & . \\
\hline $\begin{array}{l}\text { Easygoing and relaxed } \\
\text { with my child? }\end{array}$ & . & . & 4.13 & 0.82 & 3.93 & 0.78 & . & . \\
\hline No energy to make child behave? ${ }^{4}$ & . & . & 3.42 & 1.14 & 3.48 & 1.03 & . & . \\
\hline Trouble stick to rules? ${ }^{4}$ & . & . & 3.73 & 1.12 & 3.73 & 1.08 & . & . \\
\hline Hours TV? & . & . & 2.94 & 8.37 & 2.12 & 2.09 & 1.96 & 1.97 \\
\hline Number of days dinner together & . & . & 5.96 & 1.76 & 5.60 & 1.77 & 0.00 & 0.00 \\
\hline Organized athletic activities? ${ }^{1}$ & . & . & . & . & 0.37 & 0.48 & 0.51 & 0.50 \\
\hline Dance lessons? ${ }^{1}$ & . & . & . & . & 0.15 & 0.36 & 0.19 & 0.39 \\
\hline Music lessons? ${ }^{1}$ & . & . & . & . & 0.07 & 0.26 & 0.08 & 0.28 \\
\hline Drama lessons? ${ }^{1}$ & . & . & . & . & 0.01 & 0.12 & 0.02 & 0.15 \\
\hline Art classes? ${ }^{1}$ & . & . & . & . & 0.09 & 0.29 & 0.10 & 0.30 \\
\hline Organized performing arts? ${ }^{1}$ & . & . & . & . & 0.17 & 0.37 & 0.22 & 0.42 \\
\hline Craft classes or lessons? ${ }^{1}$ & . & . & . & . & 0.12 & 0.33 & 0.13 & 0.34 \\
\hline Play together with toys for building? ${ }^{1}$ & . & . & 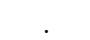 & 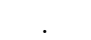 & 0.38 & 0.49 & (1) & 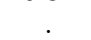 \\
\hline Computer ${ }^{1}$ & & . & . & 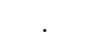 & 0.66 & 0.47 & 0.74 & 0.44 \\
\hline
\end{tabular}

Notes: '.' indicates the question was not asked in that particular round.

Responses were coded as follows:

${ }^{1} \mathrm{No}=0$, Yes $=1$

${ }^{2}$ Number times per week: not at all $=1$, once or twice $=2,3$ to 6 times $=3$, every day $=4$

${ }^{3}$ How often per month: more than once a day $=1$, about once a day $=2$, few times a week $=3$, few times a month $=4$, rarely $=5$, not at all $=6$

${ }^{4}$ Sounds like me? exactly like $=1$, very much like $=2$, somewhat like $=3$, not much like $=4$, not at all like $=5$ 
Table A.3: Child Care Quality Measurements

\begin{tabular}{|c|c|c|c|c|c|c|}
\hline & \multicolumn{2}{|c|}{$\begin{array}{c}\text { Round } 2 \\
\mathrm{~N}=1650\end{array}$} & \multicolumn{2}{|c|}{$\begin{array}{c}\text { Round } 3 \\
\mathrm{~N}=2900\end{array}$} & \multicolumn{2}{|c|}{$\begin{array}{l}\text { Round } 4 \\
\mathrm{~N}=700\end{array}$} \\
\hline & Mean & $\mathrm{SD}$ & Mean & $\mathrm{SD}$ & Mean & $\mathrm{SD}$ \\
\hline Number books & 54.50 & 89.26 & 110.89 & 169.35 & 111.58 & 164.06 \\
\hline Number records/tapes/CDs & 17.53 & 25.54 & . & . & . & . \\
\hline Number soft toys & 21.53 & 24.27 & . & . & . & . \\
\hline Number push/pull toys & 10.70 & 16.96 & . & . & . & . \\
\hline How often talk to child? ${ }^{1}$ & 3.60 & 0.60 & . & . & . & . \\
\hline Hours of TV? & . & . & 0.47 & 1.00 & 4.74 & 19.79 \\
\hline How often read books to child? ${ }^{2}$ & 3.50 & 0.83 & 6.34 & 4.69 & 5.86 & 3.86 \\
\hline How often tell stories to child? ${ }^{2}$ & 3.06 & 1.09 & 4.24 & 3.63 & 4.18 & 3.28 \\
\hline How often sing songs to child? ${ }^{2}$ & 3.60 & 0.76 & 7.10 & 6.87 & 6.46 & 6.99 \\
\hline Ask questions about story? ${ }^{3}$ & 0.91 & 1.44 & 3.21 & 0.85 & . & . \\
\hline Play chasing games? ${ }^{4}$ & 2.85 & 1.41 & . & . & . & . \\
\hline Computer? & . & . & 1.39 & 0.49 & 1.34 & 0.47 \\
\hline Play games/puzzles? & . & . & 4.26 & 3.33 & 4.11 & 2.95 \\
\hline Build something? & . & . & 3.55 & 2.99 & 3.46 & 2.72 \\
\hline Walk to yard/park/playground ${ }^{4}$ & 2.14 & 1.21 & . & . & . & . \\
\hline Visit zoo, aquarium, or petting farm $?^{5}$ & 0.12 & 0.32 & . & . & . & . \\
\hline Visited art gallery, museum, or historical site? ${ }^{5}$ & 0.06 & 0.23 & . & . & . & . \\
\hline Visited library? ${ }^{5}$ & 0.14 & 0.35 & . & . & . & . \\
\hline Reading area? ${ }^{5}$ & . & . & 0.75 & 0.43 & 0.79 & 0.41 \\
\hline Listening center? ${ }^{5}$ & . & . & 0.53 & 0.50 & 0.62 & 0.49 \\
\hline Writing center? ${ }^{5}$ & . & . & 0.71 & 0.45 & 0.78 & 0.42 \\
\hline Pocket board? ${ }^{5}$ & . & . & 0.62 & 0.49 & . & . \\
\hline Math area? ${ }^{5}$ & . & . & 0.73 & 0.45 & 0.75 & 0.43 \\
\hline Blocks? ${ }^{5}$ & . & . & 0.75 & 0.43 & 0.78 & 0.41 \\
\hline Puzzle area? ${ }^{5}$ & . & . & 0.63 & 0.48 & 0.79 & 0.41 \\
\hline Water area? ${ }^{5}$ & . & . & 0.70 & 0.46 & 0.65 & 0.48 \\
\hline Drama area? ${ }^{5}$ & . & . & 0.74 & 0.44 & 0.74 & 0.44 \\
\hline Art area? ${ }^{5}$ & . & . & 0.52 & 0.50 & 0.78 & 0.42 \\
\hline Private area? ${ }^{5}$ & . & . & 4.13 & 1.29 & . & . \\
\hline Work on learning names of letters? ${ }^{6}$ & . & . & 3.46 & 1.60 & 4.43 & 1.01 \\
\hline Practice writing the letters of the alphabet? ${ }^{6}$ & . & . & 3.95 & 1.36 & 3.93 & 1.21 \\
\hline Discuss new words? ${ }^{6}$ & . & . & 3.61 & 1.47 & 4.24 & 1.07 \\
\hline Tell stories to a caregiver/teacher/provider? ${ }^{6}$ & . & . & 4.00 & 1.38 & 3.74 & 1.29 \\
\hline Work on phonics or phonemics? ${ }^{6}$ & . & . & 4.13 & 1.29 & 4.02 & 1.30 \\
\hline Listen to stories and see print ${ }^{6}$ & . & . & 2.18 & 2.10 & 4.25 & 1.15 \\
\hline Listen to stories and don't see print? ${ }^{6}$ & . & . & 3.10 & 1.50 & 2.90 & 1.72 \\
\hline Retell stories? ${ }^{6}$ & . & . & 3.44 & 1.77 & 3.32 & 1.27 \\
\hline Learn about conventions of print ${ }^{6}$ & . & . & 3.90 & 1.55 & 3.86 & 1.41 \\
\hline Write own name? ${ }^{6}$ & . & . & 3.00 & 1.64 & 4.44 & 1.05 \\
\hline Learn about rhyming words and word families? ${ }^{6}$ & . & . & 4.58 & 0.89 & 3.28 & 1.33 \\
\hline Count out loud? ${ }^{6}$ & . & . & 3.84 & 1.39 & 4.75 & 0.68 \\
\hline Work with geometric manipulatives? ${ }^{6}$ & . & . & 3.51 & 1.64 & 3.88 & 1.24 \\
\hline Work with counting manipulatives? ${ }^{6}$ & . & . & 3.19 & 1.56 & 3.86 & 1.29 \\
\hline Play math-related games? ${ }^{6}$ & . & . & 2.45 & 1.80 & 3.46 & 1.31 \\
\hline Music for math concepts? ${ }^{6}$ & . & . & 2.21 & 1.77 & 2.78 & 1.46 \\
\hline Creative movement for math concepts? ${ }^{6}$ & . & . & 2.41 & 1.68 & 2.49 & 1.43 \\
\hline Work with measuring instruments? 6 & . & . & 3.79 & 1.84 & 2.67 & 1.35 \\
\hline Calendar activities? ${ }^{6}$ & . & . & 2.20 & 1.97 & 4.30 & 1.34 \\
\hline Telling time activites? ${ }^{6}$ & . & . & 3.83 & 1.38 & 2.88 & 1.65 \\
\hline Engage with shapes and patterns? ${ }^{6}$ & . & . & . & . & 4.08 & 1.15 \\
\hline
\end{tabular}

Notes: '.' indicates the question was not asked in that particular round.

${ }^{1}$ Typical day: $1=$ Almost never, $2=$ sometimes, $3=$ Often, $4=$ Always

${ }^{2}$ Number times per week: $1=$ Not at all, $2=$ once or twice, $3=3$ to 6 times, $4=$ Every day

3 almost never $=1$, sometimes $=2$, often $=3$, always $=4$

${ }^{4}$ more than once a day $=1$, about once a day $=2$, few times a week $=3$, few times a month $=4$,

rarely $=5$, not at all $=6$

${ }^{5} \mathrm{No}=0$, Yes $=1$

${ }^{6}$ never $=0$, once a month $=1,2$ or 3 times per month $=2,1$ or 2 a week $=3$,

3 or 4 times a week $=4$, everyday $=5$ 
Table A.4: Sample Selection Criteria

\begin{tabular}{lcc}
\hline \hline & $\mathrm{N}$ & $\begin{array}{c}\text { \% of baseline } \\
\text { sample }\end{array}$ \\
\hline Baseline sample & 10,700 & $100 \%$ \\
Exclusion criteria & & \\
Half/step siblings in house & 3,250 & $30.3 \%$ \\
Age birth less than 20, greater than 40 & 2,750 & $25.7 \%$ \\
More than two children less than age 5 & 2,250 & $21 \%$ \\
Child has a twin & 1,650 & $15.4 \%$ \\
Subsidy recipient & 1,250 & $11.7 \%$ \\
Families with step-fathers and & 950 & $8.9 \%$ \\
non-biological father figures & & \\
Biological father exits/re-enters household & 600 & $5.6 \%$ \\
Drop American Indian/Alaskan Natives & 300 & $2.8 \%$ \\
& & \\
Union of exclusion criteria & 7,700 & $72 \%$ \\
Estimation Sample & 3,000 & $28 \%$ \\
\hline Notes: Per NCES requirements, sample sizes are rounded to the nearest
\end{tabular}

Notes: Per NCES requirements, sample sizes are rounded to the nearest 50. The ECLS-B originally sampled 14,000 birth certificates but only 10,700 entered the first wave of the study. This table presents the effect of the sample selection criteria on the size of the baseline study entrants. 


\section{Appendix B: Functional Forms}

Utility:

$$
\begin{array}{lr}
U\left(C_{t}+C_{\min }\left(1-M_{t}\right), \theta_{c, t}^{1}, \theta_{c, t}^{2}, h_{L, t}, h_{c c, t}^{1}, h_{c c, t}^{2}, \epsilon_{L, t}, \epsilon_{c c, t}\right)= & \\
\frac{\left(C_{t}+C_{\min }\left(1-M_{t}\right)\right)^{1-\gamma}}{1-\gamma}+ & \text { Consumption } \\
\left(\phi_{\mathbf{K}, \mathbf{O}, \mathbf{M}}^{L, 0}+\phi^{L, 1} h_{L, t}+\epsilon_{L, t}\right) h_{L, t}+\phi^{L, 2}\left|h_{L, t}-h_{L, t-1}\right|+ & \text { Leisure } \\
+\phi^{L, 3} 1_{\left\{h_{L, t} \neq 0\right\}} & \\
\sum_{i=1}^{2}\left(\phi_{\mathbf{A}, \mathbf{q}}^{c c, 0}+\epsilon_{c c, t}\right) h_{c c, t}^{i}+\phi^{c c, 1}\left|h_{c c, t}^{i}-h_{c c, t-1}^{i}\right|+ & \text { Hours of Care } \\
\phi_{\mathbf{M}}^{c c, 2}\left(h_{w, t}-h_{c c, t}^{i}\right) 1_{\left\{h_{w, t}>h_{c c, t}^{i}\right\}} & \\
\sum_{i=1}^{2} \phi_{c} \theta_{c, t}^{i} &
\end{array}
$$

Utility parameter heterogeneity:

$$
\begin{aligned}
\phi_{\mathbf{K}, \mathbf{O}, \mathbf{M}}^{L, 0} & =\phi_{0}^{L, 0}+\phi_{1}^{L, 0} K_{t}+\phi_{2}^{L, 0} O_{t}+\phi_{3}^{L, 0} M_{t} \\
\phi_{\mathbf{A}, \mathbf{q}}^{c c, 0} & =\phi_{0}^{c c, 0}+\phi_{1}^{c c, 0} A_{t}^{i}+\phi_{2}^{c c, 0} q_{c c, t} \\
\phi_{\mathbf{M}}^{c c, 2} & =\phi_{0}^{c c, 2}+\phi_{1}^{c c, 2} M_{t}
\end{aligned}
$$

Hedonic pricing equation:

$$
p_{c c, t}=\left(\gamma_{0}^{p}+\gamma_{1}^{p} q_{c c, t}+\epsilon_{p, t}\right) 1\left\{\gamma_{0}^{p}+\gamma_{1}^{p} q_{c c, t}+\epsilon_{p, t}>0\right\}
$$


Head Start access:

$$
\begin{array}{lr}
H_{t}^{i}= & \begin{array}{r}
1\left\{\epsilon_{H S} \leq \gamma_{H S}\right\} 1\left\{A_{t}^{i} \in[3,5]\right\} \\
\\
\epsilon_{H S} \sim U[0,1]
\end{array}
\end{array}
$$

Home quality:

$$
\left.\log \left(q_{h, t}\right)=\sum_{k=0}^{1} \phi_{q h, \text { type k }} 1\{\text { type }=k\}\right)+\epsilon_{q h, t}
$$

Production Function:

$$
\begin{array}{lr}
\theta_{c, t+1}^{i}=\left(\sum_{k=0}^{1} \gamma_{0, \text { type k }}^{w} 1\{\text { type }=k\}\right)\left(\theta_{c, t}^{i}\right)^{\gamma_{1}^{c}}\left(I_{t}^{i}\right)^{\gamma_{3}^{c}} e^{\epsilon_{c, t}^{i}} & \text { Production Function } \\
I_{t}^{i}=\left(2000-h_{c c, t}^{i}\right) q_{h, t}+\alpha h_{c c, t}^{i} \bar{q}_{c c, t}^{i} & \text { Input }
\end{array}
$$

Chosen Child Care Quality:

$$
\begin{array}{r}
\bar{q}_{c c, t}^{i}=q_{c c, t}\left(1-H_{t}^{i} D_{H S, t}^{i}\right)+q_{H S, t} 1\left\{h_{c c, t}^{i}=500\right\} H_{t}^{i} D_{H S, t}^{i}+ \\
\left(.5 q_{H S, t}+.5 q_{c c, t}\right) 1\left\{h_{c c, t}^{i}=1000\right\} H_{t}^{i} D_{H S, t}^{i}
\end{array}
$$

Wage offer function:

$$
\begin{array}{r}
\log \left(w_{t}\right)=\quad \sum_{k=0}^{1} \gamma_{0, \text { type k }}^{w} 1\{\text { type }=k\}+\gamma_{1}^{w} \text { black }+\gamma_{2}^{w} E_{w}+\gamma_{3}^{w} X_{w, t}+ \\
\gamma_{4}^{w} X_{w, t}^{2}+\mu_{w}+\epsilon_{w, t}
\end{array}
$$


Husband's income:

$$
\begin{array}{r}
\log \left(I_{t}\right)=\quad \sum_{k=0}^{1} \gamma_{0, \text { type } \mathrm{k}}^{h} 1\{\text { type }=k\}+\gamma_{1}^{h} \text { black }+\gamma_{2}^{h} E_{h}+\gamma_{3}^{h} X_{h, t}+ \\
\gamma_{4}^{h} X_{h, t}^{2}+\mu_{I}+\epsilon_{I, t}
\end{array}
$$

Probability of a birth:

$$
\begin{gathered}
P\left(K_{t+1}=K_{t}+1 \mid X_{t}^{b}\right)=\frac{1}{1+\exp \left(-X_{t}^{b} \boldsymbol{\phi}^{b}\right)} \\
P\left(K_{t+1}=K_{t}+1 \mid X_{t}^{b}, K_{t}=2\right)=0 \\
X_{t}^{b} \boldsymbol{\phi}^{\boldsymbol{b}}=\phi_{0}^{b}+\phi_{1}^{b} E_{w}+\phi_{2}^{b} \text { black }+\phi_{3}^{b} t+\phi_{4}^{b} M_{t}+ \\
\phi_{5}^{b} E_{h} M_{t}+\phi_{6}^{b} X_{h, t} M_{t}+\phi_{7}^{b} K_{t}+\phi_{8}^{b} O_{t}
\end{gathered}
$$

Evolution of age, younger and older children:

$$
\begin{aligned}
& A_{t+1}^{i}=A_{t}^{i}+.5 \\
& O_{t+1}=O_{t}+1\left\{A_{t}^{1}>5\right\}+1\left\{A_{t}^{2}>5\right\} \\
& K_{t+1}=K_{t}-1\left\{A_{t}^{1}>5\right\}-1\left\{A_{t}^{2}>5\right\}+1\left\{\epsilon_{b} \leq P\left(K_{t+1}=K_{t}+1 \mid X_{t}^{b}\right)\right\} \\
& \epsilon_{b} \sim U(0,1)
\end{aligned}
$$


Probability of a divorce:

$$
\begin{aligned}
& P\left(M_{t+1}=0 \mid M_{t}=1, X_{t}^{d}\right)=\frac{1}{1+\exp \left(-X_{t}^{d} \boldsymbol{\phi}^{d}\right)} \\
& P\left(M_{t+1}=1 \mid M_{t}=0\right)=0 \\
& X_{t}^{d} \boldsymbol{\phi}^{d}=\phi_{0}^{d}+\phi_{1}^{d} E_{w}+\phi_{3}^{d} \text { black }+\phi_{4}^{d} t+\phi_{5}^{d} E_{h}+\phi_{6}^{d} X_{h, t}+\phi_{7}^{d} K_{t}+\phi_{8}^{d} O_{t}
\end{aligned}
$$

Evolution of marriage:

$$
\begin{aligned}
& M_{t+1}=M_{t}-1\left\{\epsilon_{d} \leq P\left(M_{t+1}=0 \mid M_{t}, X_{t}^{d}\right)\right\} \\
& \epsilon_{d} \sim U(0,1)
\end{aligned}
$$

State space:

$$
\begin{aligned}
\Omega_{t}= & \left\{X_{f, t}, E_{f}, X_{m, t}, E_{m}, \text { black }, h_{L, t-1}, h_{c c, t-1}^{1}, h_{c c, t-1}^{2}, A_{t}^{1}, A_{t}^{2}, O_{t},\right. \\
& \left.M_{t}, \theta_{c, t}^{1} \theta_{c, t}^{2}, \theta_{c, t}^{T}, q_{c c, t}, p_{c c, t}, q_{H S, t}, H_{t}^{1}, H_{t}^{2}, \epsilon_{c, t}^{1}, \epsilon_{c, t}^{2}, \epsilon_{q h, t}, \epsilon_{L, t}, \epsilon_{c c, t}, \epsilon_{w, t}, \epsilon_{I, t}\right\}
\end{aligned}
$$

Unobserved heterogeneity:

$$
\begin{aligned}
& \operatorname{Pr}\left(\text { type }=1 \mid Z_{0}\right)=\frac{1}{1+\exp \left(-Z_{0} \boldsymbol{\beta}_{\text {type }}\right)} \\
& \operatorname{Pr}\left(\text { type }=2 \mid Z_{0}\right)=1-\operatorname{Pr}\left(\text { type }=1 \mid Z_{0}\right)
\end{aligned}
$$

with

$$
\begin{aligned}
Z_{0} \boldsymbol{\beta}_{\text {type }}= & \beta_{0, \text { type }}+\beta_{1, \text { type }} \text { black }+\beta_{2, \text { type }} E_{w}+\beta_{3, \text { type }} t_{0}+ \\
& \beta_{4, \text { type }} M_{0}+\beta_{5, \text { type }} M_{0} E_{h}+\beta_{6, \text { type }} M_{0} X_{h, 0}
\end{aligned}
$$




\section{Appendix C: Parameters and Model Fit}

Table C.1: Parameter Estimates

\begin{tabular}{|c|c|c|c|}
\hline Description & Parameter & Estimate & Standard Error \\
\hline \multicolumn{4}{|l|}{ Utility } \\
\hline CRRA & $\gamma$ & $0.952 *$ & 0.051 \\
\hline Utility cognitive skills & $\phi_{c}$ & 0.015 & 0.05 \\
\hline Utility leisure & $\phi^{L 0}$ & 0.002 & 0.022 \\
\hline Diminishing returns to leisure & $\phi^{L 1}$ & -0.24 & 0.215 \\
\hline Leisure $\mathrm{X}$ younger children & $\phi_{1}^{L 0}$ & 0.013 & 0.191 \\
\hline Leisure X older children & $\phi_{2}^{L 0}$ & 0.008 & 0.096 \\
\hline Leisure X marital status & $\phi_{3}^{L 0}$ & 0.007 & 0.088 \\
\hline Switching costs leisure & $\phi^{L 2}$ & $-1.8^{*}$ & 0.879 \\
\hline Fixed cost of working & $\phi^{L 3}$ & -0.014 & 0.098 \\
\hline Variance leisure shock & $\sigma_{L}^{2}$ & 2.991 & 1.759 \\
\hline Utility child care & $\phi_{0}^{c c 0}$ & $-0.882 *$ & 0.226 \\
\hline Utility child care $\mathrm{X}$ child age & $\phi_{1}^{c c 0}$ & 0.021 & 0.032 \\
\hline Utility child care X quality & $\phi_{2}^{c c 0}$ & 0.002 & 0.043 \\
\hline Switching costs child care & $\phi^{c c 1}$ & $-0.583 *$ & 0.226 \\
\hline Disutility work and no care & $\phi_{0}^{c c 2}$ & $-1.713 *$ & 0.449 \\
\hline Disutility work and no care $\mathrm{X}$ divorced & $\phi_{1}^{c c 2}$ & -0.324 & 0.612 \\
\hline Variance child care utility shock & $\sigma_{c c}^{2}$ & $2.55^{*}$ & 1.212 \\
\hline Continuation value cognitive skills & $A_{c}$ & 2.046 & 2.055 \\
\hline Continuation value mother experience & $A_{w}$ & 0.003 & 0.071 \\
\hline Discount factor & $\beta$ & $0.9^{*}$ & 0.095 \\
\hline$\%$ transfered to wife & $\tau_{0}$ & 0.991 & 1 \\
\hline$\%$ transfered to wife $\mathrm{X}$ black & $\tau_{1}$ & 0.957 & 0.99 \\
\hline \multicolumn{4}{|c|}{ Cognitive achievement production function } \\
\hline Intecept type 0 & $\gamma_{0, \text { type } 0}^{c}$ & 0.053 & 0.032 \\
\hline
\end{tabular}


Intercept type 1

$$
\gamma_{0}^{c}
$$

Value-added

Share parameter

$\begin{array}{ccc}\gamma_{0, \text { type } 1}^{c} & 0.01 & 0.012 \\ \gamma_{1}^{c} & 0.792^{*} & 0.107 \\ \alpha & 0.586 & 0.392 \\ \gamma_{3}^{c} & 0.428^{*} & 0.089 \\ \sigma_{c}^{2} & 0 & 0.008\end{array}$

Scale parameter

Variance of cognitive skill shock

Child care quality offer distribution

$\begin{array}{lccr}\text { Mean quality } & \mu_{c c q} & 0.051 & 0.146 \\ \text { Variance quality } & \sigma_{c c q}^{2} & 0.65 * & 0.166\end{array}$

Hedonic equation

Hedonic intercept

$\begin{array}{lll}\gamma_{0}^{p} & 4.091^{*} & 0.999\end{array}$

Hedonic quality

$\begin{array}{lll}\gamma_{1}^{p} & 0.257 & 0.562\end{array}$

Hedonic shock variance

$\sigma_{p}^{2} \quad 15.35 *$

2.893

\section{Head Start}

Mean HS quality

$\begin{array}{ccc}\mu_{H S q} & 0.697 & 0.623 \\ \sigma_{H S q}^{2} & 0.16 & 0.229 \\ \gamma_{H S} & 0.744 & 0.699\end{array}$

Probability Head Start Offer

0.744

Home quality

$\begin{array}{lccr}\text { Intercept type 0 } & \phi_{q h, \text { type 0 }} & -0.856^{*} & 0.367 \\ \text { Intercept type 1 } & \phi_{q h \text {,type 1 }} & 1.087^{*} & 0.375 \\ \text { Variance home quality shock } & \sigma_{q_{h}}^{2} & 0.808 & 0.423\end{array}$

Wage offer equation

$\begin{array}{lccc}\text { Intercept type } 0 & \gamma_{0, \text { type } 0}^{w} & 0.001 & 0.018 \\ \text { Intercept type } 1 & \gamma_{0, \text { type } 1}^{w} & 0.555 & 0.309 \\ \text { Black } & \gamma_{1}^{w} & -0.034 & 0.355 \\ \text { Returns to education } & \gamma_{2}^{w} & 0.127^{*} & 0.019 \\ \text { Variance wage shock } & \sigma_{w}^{2} & 0.049 & 0.084\end{array}$

Income equation

Intercept type 0

Intercept type 1

Black

Returns to education

$\begin{array}{ccc}\gamma_{0, \text { type } 0}^{h} & 7.315^{*} & 0.687 \\ \gamma_{0, \text { type } 1}^{h} & 0.86 & 0.502 \\ \gamma_{1}^{h} & -0.169 & 0.472 \\ \gamma_{2}^{h} & 0.109 * & 0.042\end{array}$


Returns to experience

$\begin{array}{ccc}\gamma_{3}^{h} & 0.113^{*} & 0.041 \\ \gamma_{4}^{h} & -0.004 * & 0.001 \\ \sigma_{I}^{2} & 0.009 & 0.023\end{array}$

Variance income shock

Divorce logit

Intercept

$\begin{array}{lll}\phi_{0}^{d} & -3.776 & 6.549\end{array}$

Mother education

$\phi_{1}^{d}$

$-0.034$

0.11

Black

$\begin{array}{lll}\phi_{2}^{d} & 0.098 & 0.528\end{array}$

Mother age

$\begin{array}{lll}\phi_{3}^{d} & 0.034 & 0.051\end{array}$

Father education

$\begin{array}{lll}\phi_{4}^{d} & -0.332 & 0.579\end{array}$

Father experience

$\begin{array}{lll}\phi_{5}^{d} & -0.014 & 0.069\end{array}$

Number younger kids

$\begin{array}{lll}\phi_{6}^{d} & 0.595 & 1.035\end{array}$

Number older kids

$\begin{array}{lll}\phi_{7}^{d} & 0.713 & 0.569\end{array}$

Fertility logit

Intercept

Mother education

Black

Mother age

Father education X marital status

Number of younger kids

Number of older kids

$\phi_{0}^{b}$

$\phi_{1}^{b}$

$-1.524 *$

0.349

$\phi_{2}^{b}$

$-0.001$

0.006

0.561

$\phi_{3}^{b}$

$-0.008$

0.012

$\phi_{4}^{b} \quad 0.001$

0.008

$\phi_{5}^{b} \quad 0.001$

0.011

$\phi_{6}^{b}$

$-0.154$

0.134

\section{Type probability}

$\begin{array}{lccc}\text { Intercept } & \beta_{\text {0type }} & -2.75 * & 1.166 \\ \text { Black } & \beta_{\text {1type }} & -0.037 & 8.54 \\ \text { Mother education } & \beta_{2 t y p e} & 0.136 & 0.115 \\ \text { Mother age at first birth } & \beta_{\text {3type }} & 0.05 & 0.071 \\ \text { Initial marital status } & \beta_{\text {4type }} & 0.32 & 0.673 \\ \text { Father education X marital status } & \beta_{5 t y p e} & 0.059 & 0.076 \\ \text { Father initial experience X marital status } & \beta_{6 t y p e} & -0.048 & 0.072\end{array}$

Notes: $*$ indicates statistically significant at the $5 \%$ level. There are 73 parameters. 
Table C.2: Ancillary Statistics

\begin{tabular}{lccccc}
\hline \hline Elasticities & & & \\
Wage Elasticity of Labor Supply (intensive) & 0.92 & & \\
Wage Elasticity of Labor Supply (extensive) & 0.88 & & & \\
Cognitive skills & & & & \\
\hline Intra-sibling correlation in cognitive skills & 0.49 & & & \\
Average cognitive skills by birth order: & & & & \\
& & & Family size \\
Birth order & Unconditional & 1 & 2 & 3 \\
First born & -0.02 & 0.17 & 0.2 & -0.1 \\
Second born & -0.07 & - & 0.15 & -0.15 \\
Third born & -0.2 & - & - & -0.2 \\
\hline \hline
\end{tabular}

Notes: The wage elasiticty considers the average change in labor force participation given a $5 \%$ increase in the wage in every period for every woman. The estimated elasticity is uncompensated. 
MODEL FIT

Table C.3: Basic Statistics

\begin{tabular}{lcc}
\hline \hline & Data & Model \\
Average Cognitive Skills & 0.00 & $\mathbf{0 . 0 1}$ \\
Average Home Quality & 1.38 & $\mathbf{1 . 4 4}$ \\
Average Child Care Quality & 1.41 & $\mathbf{1 . 4 5}$ \\
Average Price Child Care / Hour $(\$)$ & 4.39 & $\mathbf{4 . 4 7}$ \\
Percent Full Time Child Care & 0.33 & $\mathbf{0 . 3 4}$ \\
Percent Part Time Child Care & 0.14 & $\mathbf{0 . 1 0}$ \\
\% in Head Start & 0.04 & $\mathbf{0 . 0 2}$ \\
Average Head Start Quality & 2.30 & $\mathbf{2 . 2 7}$ \\
Percent Full Time Labor & 0.44 & $\mathbf{0 . 4 4}$ \\
Percent Part Time Labor & 0.09 & $\mathbf{0 . 1 2}$ \\
Average Female Wage $(\$)$ & 21.76 & $\mathbf{2 3 . 0 3}$ \\
Average Husband Income $(\$)$ & 28,767 & $\mathbf{2 9 , 1 5 6}$ \\
\% Labor Force Participation & 0.57 & $\mathbf{0 . 5 6}$ \\
\% Child Care Participation & 0.46 & $\mathbf{0 . 4 4}$ \\
\% Married & 0.95 & $\mathbf{0 . 9 5}$ \\
Average Number Younger Children & 1.53 & $\mathbf{1 . 5 3}$ \\
Average Number Older Children & 0.39 & $\mathbf{0 . 3 9}$ \\
\hline \hline
\end{tabular}




\section{MODEL FIT: Cognitive Skills}

Table C.4: Average Cognitive Skills By Household Characteristics

\begin{tabular}{lcc}
\hline \hline & Data & Model \\
Married & 0.02 & $\mathbf{0 . 0 3}$ \\
Single & -0.39 & $\mathbf{- 0 . 3 9}$ \\
White & 0.10 & $\mathbf{0 . 0 3}$ \\
Black & -0.32 & $\mathbf{- 0 . 2 1}$ \\
Mother less than H.S. & -0.43 & $\mathbf{- 0 . 3 7}$ \\
Mother H.S. & -0.28 & $\mathbf{- 0 . 1 8}$ \\
Mother Some college & -0.10 & $\mathbf{- 0 . 0 4}$ \\
Mother College+ & 0.26 & $\mathbf{0 . 1 9}$ \\
Standard deviation & 1.00 & $\mathbf{0 . 9 4}$ \\
\hline \hline
\end{tabular}




\section{MODEL FIT: Child Care Participation}

Table C.5: \% in Child Care By Household Characteristics

\begin{tabular}{lcc}
\hline \hline & Data & Model \\
Married & 0.45 & $\mathbf{0 . 4 4}$ \\
Single & 0.59 & $\mathbf{0 . 3 7}$ \\
White & 0.47 & $\mathbf{0 . 4 4}$ \\
Black & 0.53 & $\mathbf{0 . 4 3}$ \\
Mother less than H.S. & 0.27 & $\mathbf{0 . 2 4}$ \\
Mother H.S. & 0.41 & $\mathbf{0 . 3 3}$ \\
Mother Some college & 0.44 & $\mathbf{0 . 4 1}$ \\
Mother College+ & 0.54 & $\mathbf{0 . 5 4}$ \\
\hline \hline
\end{tabular}




\section{MODEL FIT: Child Care Quality}

Table C.6: Average Child Care Quality By Household Characteristics

\begin{tabular}{lcc}
\hline \hline & Data & Model \\
Married & 1.40 & $\mathbf{1 . 4 4}$ \\
Single & 1.50 & $\mathbf{1 . 5 2}$ \\
White & 1.39 & $\mathbf{1 . 4 4}$ \\
Black & 1.65 & $\mathbf{1 . 4 5}$ \\
Mother less than H.S. & 1.48 & $\mathbf{1 . 5 4}$ \\
Mother H.S. & 1.46 & $\mathbf{1 . 4 9}$ \\
Mother Some college & 1.28 & $\mathbf{1 . 4 1}$ \\
Mother College+ & 1.46 & $\mathbf{1 . 4 5}$ \\
\hline \hline
\end{tabular}

\section{MODEL FIT: Child Care Price}

Table C.7: Average Child Care Price By Household Characteristics

\begin{tabular}{lcc}
\hline \hline Married & 4.46 & $\mathbf{4 . 5 1}$ \\
Single & 2.92 & $\mathbf{3 . 5 2}$ \\
White & 4.61 & $\mathbf{4 . 4 9}$ \\
Black & 3.77 & $\mathbf{4 . 2 0}$ \\
Mother less than H.S. & 2.49 & $\mathbf{3 . 6 4}$ \\
Mother H.S. & 3.10 & $\mathbf{4 . 1 1}$ \\
Mother Some college & 3.73 & $\mathbf{4 . 4 8}$ \\
Mother College+ & 5.11 & $\mathbf{4 . 6 2}$ \\
\hline \hline
\end{tabular}




\section{MODEL FIT: Head Start}

Table C.8: Head Start Participation By Household Characteristics

\begin{tabular}{lcc}
\hline \hline & Data & Model \\
Average Head Start Quality & 2.30 & $\mathbf{2 . 2 7}$ \\
SD Quality & 0.99 & $\mathbf{1 . 0 0}$ \\
Married & 0.04 & $\mathbf{0 . 0 2}$ \\
Single & 0.11 & $\mathbf{0 . 1 6}$ \\
White & 0.03 & $\mathbf{0 . 0 2}$ \\
Black & 0.09 & $\mathbf{0 . 0 6}$ \\
Mother less than H.S. & 0.10 & $\mathbf{0 . 1 1}$ \\
Mother H.S. & 0.08 & $\mathbf{0 . 0 5}$ \\
Mother Some college & 0.05 & $\mathbf{0 . 0 1}$ \\
Mother College+ & 0.01 & $\mathbf{0 . 0 0}$ \\
\hline \hline
\end{tabular}




\section{MODEL FIT: Home Quality}

Table C.9: Average Home Quality By Household Characteristics

\begin{tabular}{lcc}
\hline \hline & Data & Model \\
Married & 1.40 & $\mathbf{1 . 4 6}$ \\
Single & 1.03 & $\mathbf{1 . 1 8}$ \\
White & 1.50 & $\mathbf{1 . 4 5}$ \\
Black & 1.09 & $\mathbf{1 . 3 1}$ \\
Mother less than H.S. & 0.74 & $\mathbf{1 . 1 2}$ \\
Mother H.S. & 1.10 & $\mathbf{1 . 2 2}$ \\
Mother Some college & 1.33 & $\mathbf{1 . 3 8}$ \\
Mother College+ & 1.65 & $\mathbf{1 . 6 4}$ \\
\hline \hline
\end{tabular}




\section{MODEL FIT: Labor Force Participation}

Table C.10: \% in Labor Force By Household Characteristics

\begin{tabular}{lcc}
\hline \hline & Data & Model \\
Married & 0.57 & $\mathbf{0 . 5 6}$ \\
Single & 0.59 & $\mathbf{0 . 5 6}$ \\
White & 0.58 & $\mathbf{0 . 5 6}$ \\
Black & 0.64 & $\mathbf{0 . 6 0}$ \\
Mother less than H.S. & 0.36 & $\mathbf{0 . 3 8}$ \\
Mother H.S. & 0.50 & $\mathbf{0 . 4 6}$ \\
Mother Some college & 0.59 & $\mathbf{0 . 5 3}$ \\
Mother College+ & 0.63 & $\mathbf{0 . 6 6}$ \\
\hline \hline
\end{tabular}




\section{MODEL FIT: Distribution and Transition of Decisions \\ Table C.11}

Distribution of Care/Work Decisions: Data, Model

Round $\mathrm{T}$

Round T

No Work Part-Time Work Full-Time Work

No Child Care

$$
0.38, \mathbf{0 . 4 1} \quad 0.04, \mathbf{0 . 0 4}
$$

$0.11,0.11$

Part-Time Child Care

$0.05, \mathbf{0 . 0 1}$

$0.03, \mathbf{0 . 0 7}$

$0.05, \mathbf{0 . 0 2}$

Full-Time Child Care

$0.03, \mathbf{0 . 0 2}$

$0.00, \mathbf{0 . 0 1}$

$0.27, \mathbf{0 . 3 1}$

Child Care Transition Between Rounds: Data, Model

\begin{tabular}{lcccc}
\hline & \multicolumn{5}{c}{ Round $\mathrm{T}$} \\
Round T-1 & No Care & Part-Time Care & Full-Time Care \\
No Child Care & $0.67, \mathbf{0 . 6 7}$ & $0.16, \mathbf{0 . 0 9}$ & $0.17, \mathbf{0 . 2 4}$ \\
Part-Time Child Care & $0.28, \mathbf{0 . 2 6}$ & $0.33, \mathbf{0 . 4 7}$ & $0.39, \mathbf{0 . 2 7}$ \\
Full-Time Child Care & $0.20, \mathbf{0 . 2 5}$ & $0.09, \mathbf{0 . 0 6}$ & $0.71, \mathbf{0 . 6 9}$ \\
& & & \\
Work Transition Between Rounds: Data, Model \\
\hline \multicolumn{5}{c}{ Round T } \\
Round T-1 & No Work & Part-Time Work & Full-Time Work \\
No Work & $0.78, \mathbf{0 . 7 5}$ & $0.07, \mathbf{0 . 0 9}$ & $0.15, \mathbf{0 . 1 6}$ \\
Part-Time Work & $0.26, \mathbf{0 . 0 3}$ & $0.39, \mathbf{0 . 7 3}$ & $0.35, \mathbf{0 . 2 4}$ \\
Full-Time Work & $0.13, \mathbf{0 . 0 2}$ & $0.05, \mathbf{0 . 0 2}$ & $0.82, \mathbf{0 . 9 6}$
\end{tabular}




\section{MODEL FIT: Wages}

\section{Table C.12}

Average Wage By Mother's Characteristics

\begin{tabular}{lcc}
\hline \hline & Data & Model \\
Married & 22.17 & $\mathbf{2 3 . 3 5}$ \\
Single & 13.82 & $\mathbf{1 6 . 4 4}$ \\
White & 23.66 & $\mathbf{2 3 . 3 2}$ \\
Black & 17.21 & $\mathbf{1 9 . 1 4}$ \\
Mother less than H.S. & 9.31 & $\mathbf{9 . 1 3}$ \\
Mother H.S. & 12.45 & $\mathbf{1 2 . 6 6}$ \\
Mother Some college & 16.94 & $\mathbf{1 7 . 3}$ \\
Mother College + & 29.14 & $\mathbf{3 0 . 4 1}$ \\
\hline \hline
\end{tabular}




\section{MODEL FIT: Income}

\section{Table C.13}

Average Income By Father's Characteristics

\begin{tabular}{lcc}
\hline \hline & Data & Model \\
White & 31,890 & $\mathbf{2 9 , 8 1 5}$ \\
Black & 21,064 & $\mathbf{1 9 , 7 2 8}$ \\
Father less than H.S. & 12,128 & $\mathbf{1 1 , 0 0 3}$ \\
Father H.S. & 18,978 & $\mathbf{1 7 , 3 7 0}$ \\
Father Some college & 23,697 & $\mathbf{2 3 , 9 1 9}$ \\
Father College+ & 39,430 & $\mathbf{4 1 , 5 6 8}$ \\
Father Experience 0-5 & 18,732 & $\mathbf{2 5 , 0 3 0}$ \\
Father Experience 5-10 & 24,979 & $\mathbf{3 1 , 6 8 7}$ \\
Father Experience 10-15 & 31,662 & $\mathbf{3 6 , 6 9 2}$ \\
Father Experience 15-20 & 31,721 & $\mathbf{3 3 , 0 1 2}$ \\
Father Experience 20-25 & 26,227 & $\mathbf{2 4 , 9 9 5}$ \\
Father Experience 25+ & 21,636 & $\mathbf{1 0 , 1 5 4}$ \\
\hline \hline
\end{tabular}




\section{MODEL FIT: Number of Younger Children}

\section{Table C.14}

Average Number of Younger Children By Household Characteristics

\begin{tabular}{lcc}
\hline \hline & Data & Model \\
Married & 1.53 & $\mathbf{1 . 5 3}$ \\
Single & 1.47 & $\mathbf{1 . 5 0}$ \\
White & 1.54 & $\mathbf{1 . 5 3}$ \\
Black & 1.48 & $\mathbf{1 . 5 4}$ \\
Mother less than H.S. & 1.47 & $\mathbf{1 . 5 4}$ \\
Mother H.S. & 1.52 & $\mathbf{1 . 5 4}$ \\
Mother Some college & 1.54 & $\mathbf{1 . 5 3}$ \\
Mother College+ & 1.53 & $\mathbf{1 . 5 3}$ \\
\hline
\end{tabular}




\section{Figure F.1}

Younger Children By Mother's Age

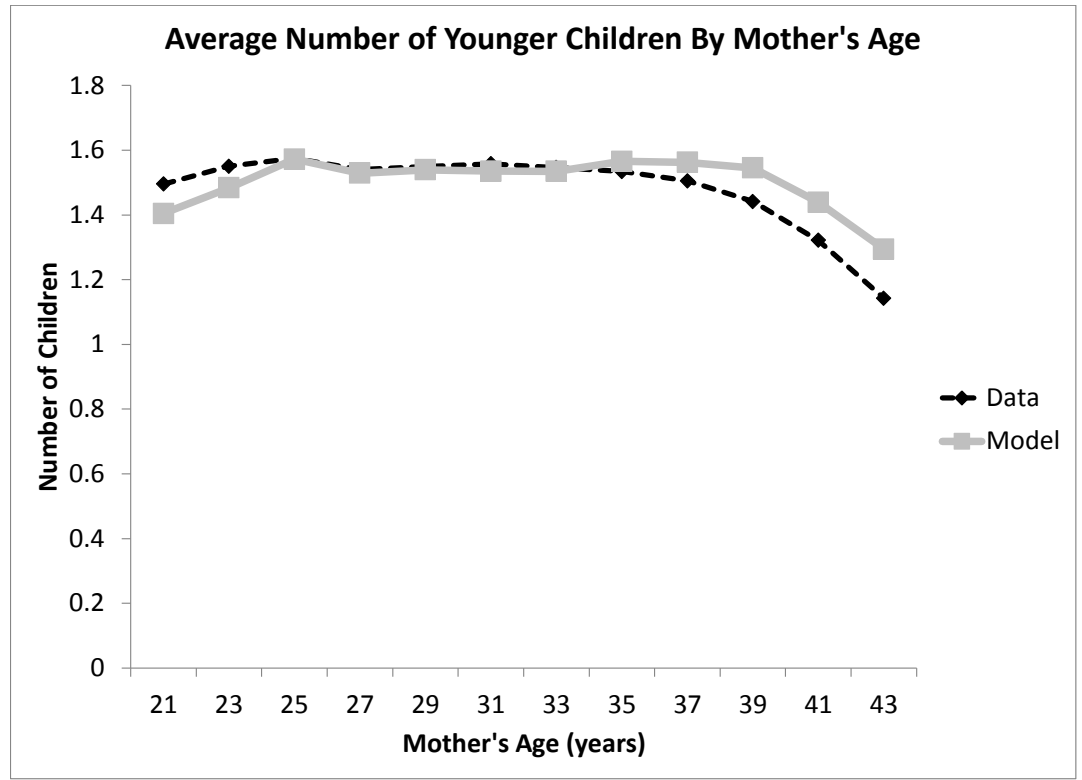




\section{MODEL FIT: Number of Older Children}

\section{Table C.15}

Average Number of Older Children By Household Characteristics

\begin{tabular}{lcc}
\hline \hline & Data & Model \\
Married & 0.38 & $\mathbf{0 . 3 6}$ \\
Single & 0.62 & $\mathbf{0 . 9 3}$ \\
White & 0.34 & $\mathbf{0 . 3 7}$ \\
Black & 0.63 & $\mathbf{0 . 5 7}$ \\
Mother less than H.S. & 0.60 & $\mathbf{0 . 5 7}$ \\
Mother H.S. & 0.49 & $\mathbf{0 . 4 9}$ \\
Mother Some college & 0.44 & $\mathbf{0 . 4 3}$ \\
Mother College+ & 0.27 & $\mathbf{0 . 2 8}$ \\
\hline
\end{tabular}




\section{Figure F.2:}

Older Children By Mother's Age

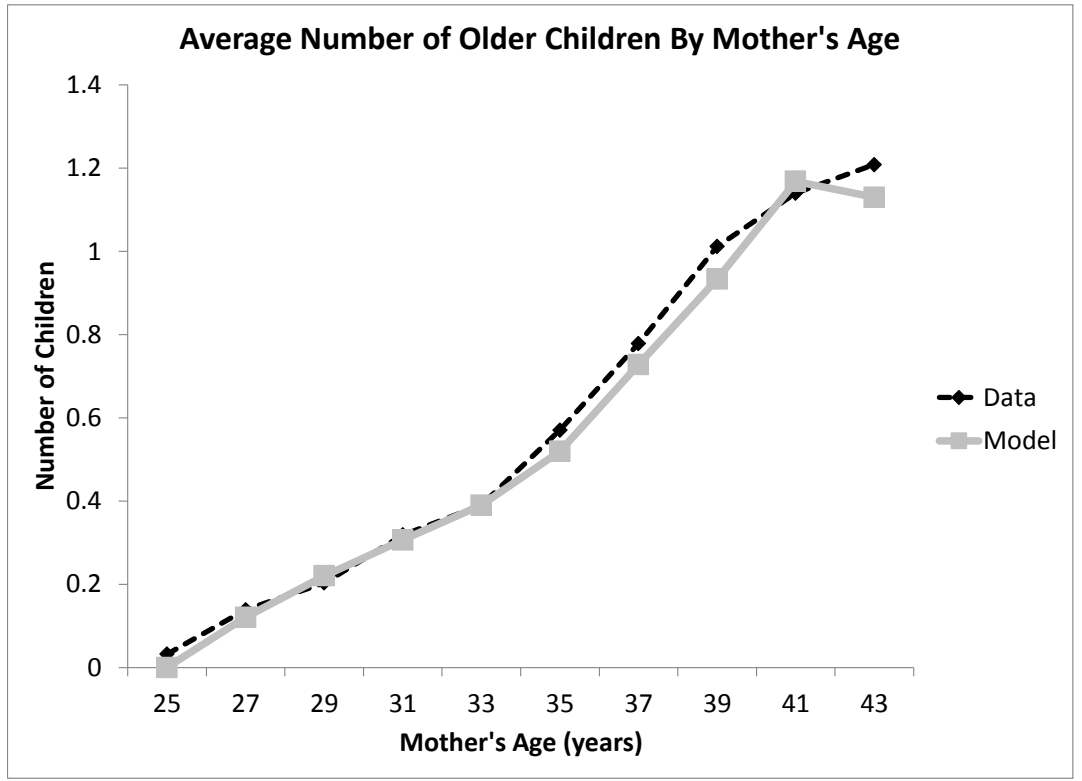




\section{MODEL FIT: Marriage}

Table C.16

Percent Married By Household Characteristics

\begin{tabular}{lcc}
\hline \hline & Data & Model \\
White & 0.97 & $\mathbf{0 . 9 7}$ \\
Black & 0.72 & $\mathbf{0 . 7 3}$ \\
Mother less than H.S. & 0.88 & $\mathbf{0 . 8 6}$ \\
Mother H.S. & 0.91 & $\mathbf{0 . 9 2}$ \\
Mother Some college & 0.94 & $\mathbf{0 . 9 4}$ \\
Mother College+ & 0.99 & $\mathbf{0 . 9 9}$ \\
\hline
\end{tabular}

Figure F.3:

Percent Married By Mother's Age

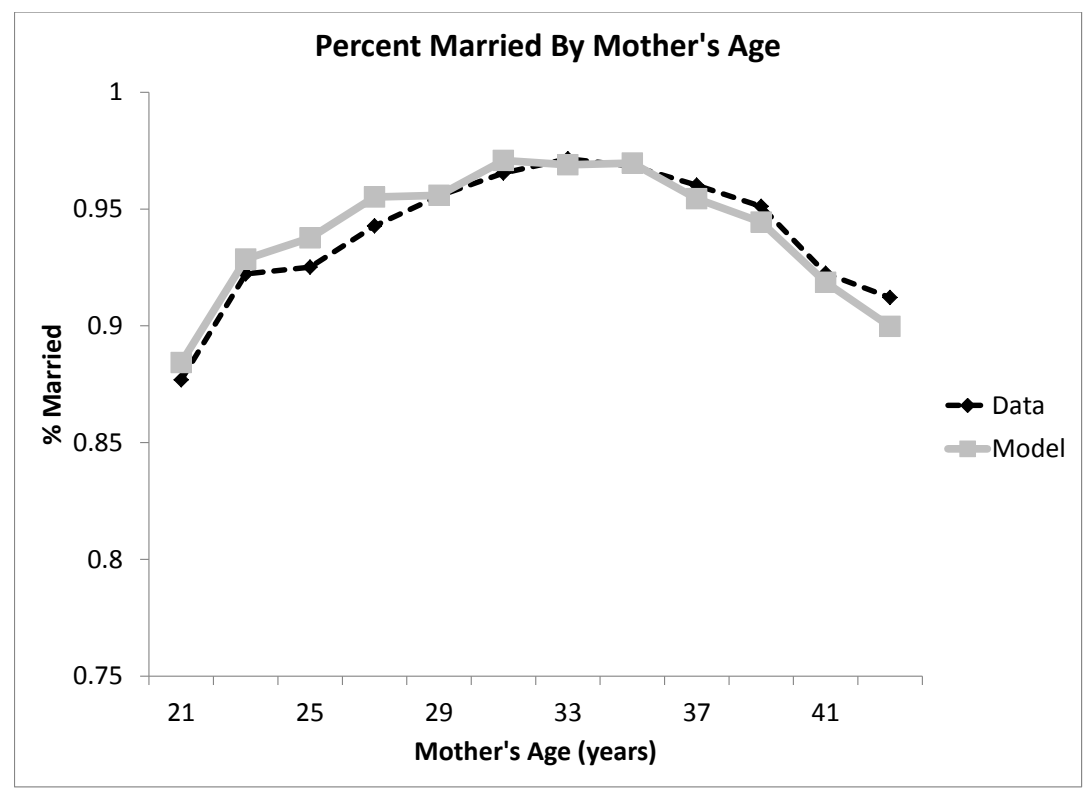


Figure F.4:

Cognitive Gaps by Maternal Education and Child's Age
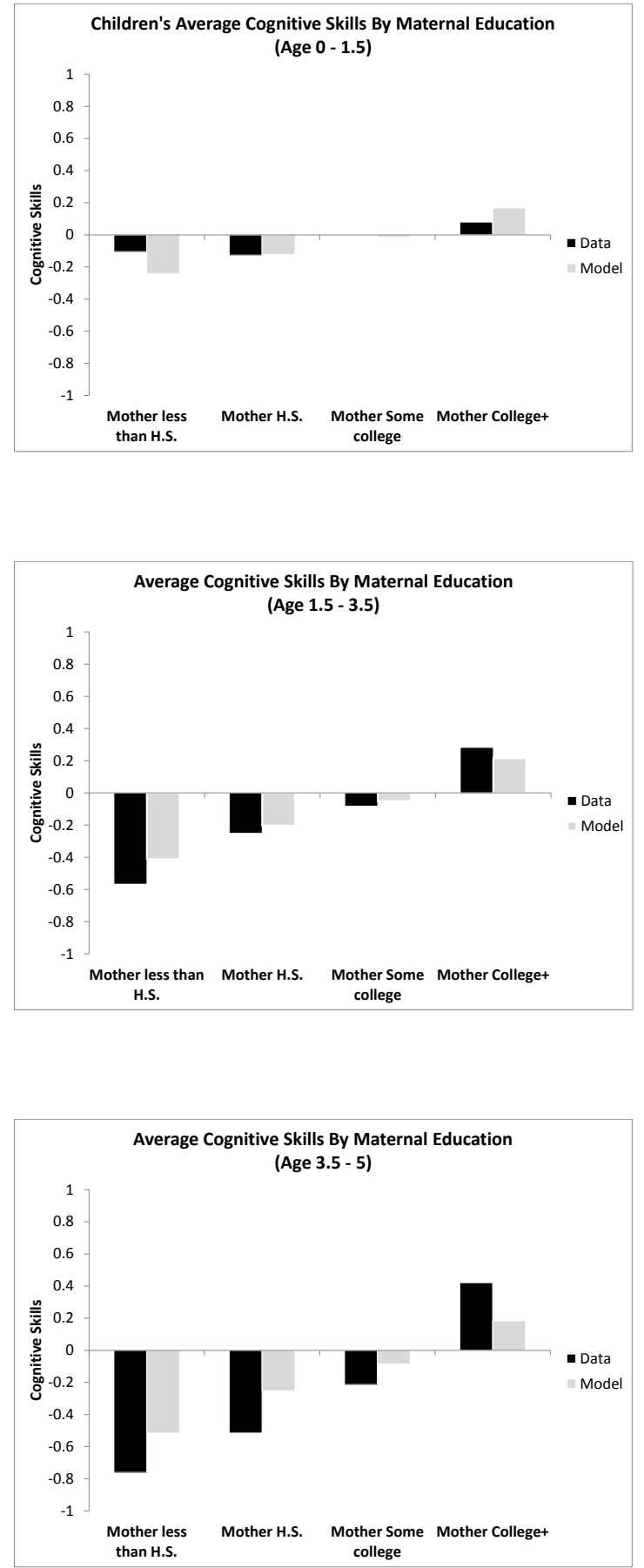
Figure F.5:

Cognitive Gaps by Child's Age and Race

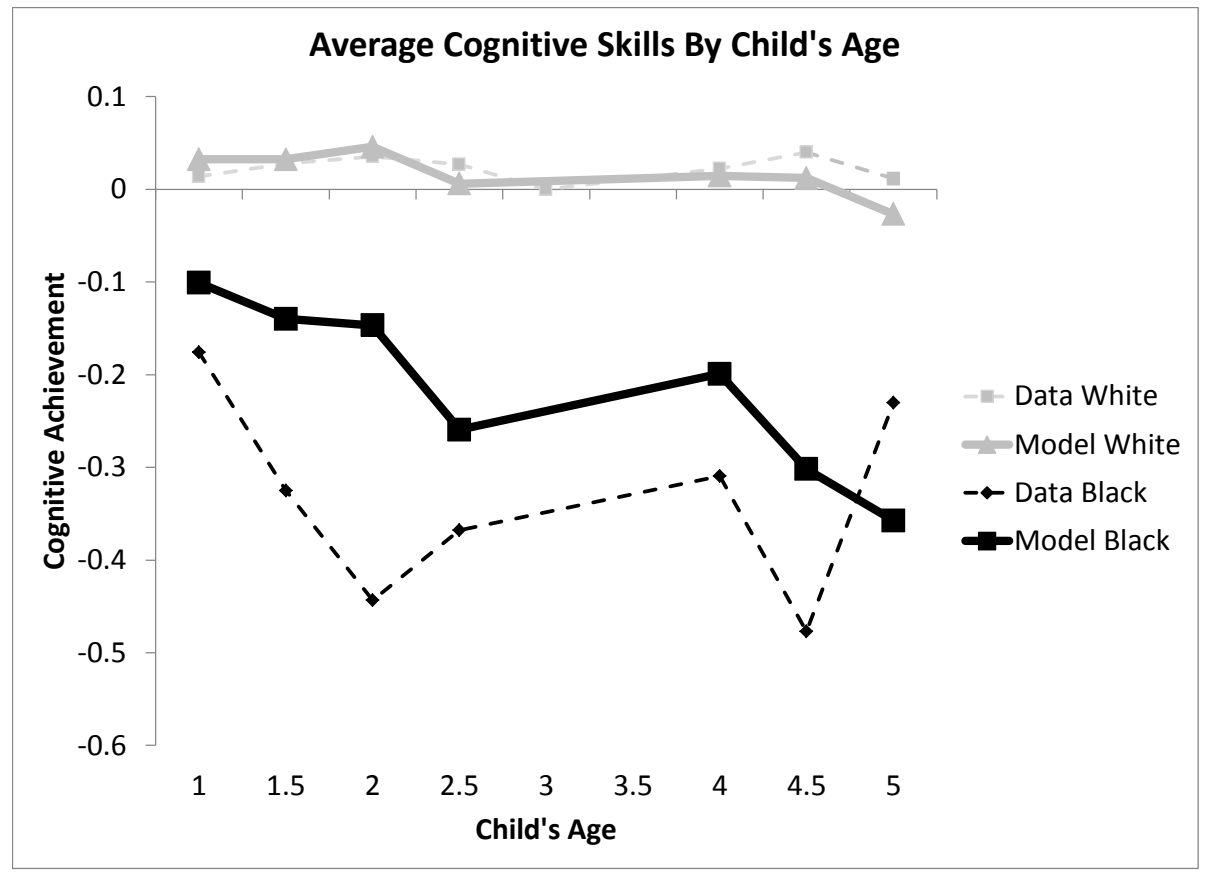


Figure F.6:

Average Child Care Quality by Child's Age and Race

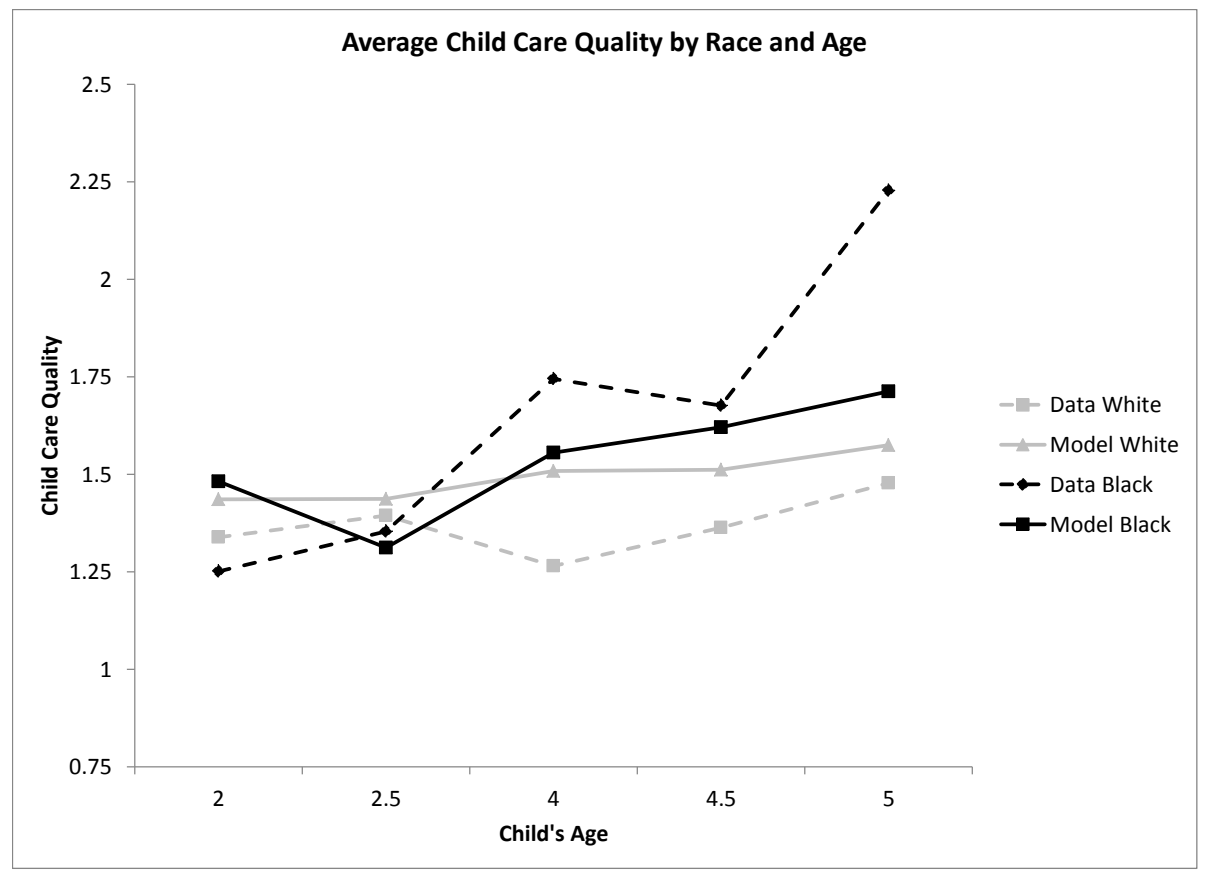




\section{Appendix D: Counterfactuals}

Table D.1: Model Validation: Model Experiment vs. Head Start Impact Study (HSIS)

\begin{tabular}{lcccc} 
& \multicolumn{2}{c}{ Intent to Treat } & \multicolumn{2}{c}{ Treatment on the Treated } \\
& $\begin{array}{c}\text { Model } \\
\text { Cognitive }\end{array}$ & $\begin{array}{c}\text { HSIS } \\
\text { Cognitive }\end{array}$ & $\begin{array}{c}\text { Model } \\
\text { Cognitive }\end{array}$ & $\begin{array}{c}\text { HSIS } \\
\text { Cognitive }\end{array}$ \\
\hline \hline Design & & & & \\
HSIS 4 year olds & 0.06 & 0.12 & 0.12 & 0.17 \\
HSIS 3 year olds & 0.07 & 0.05 & 0.13 & 0.06 \\
\hline \hline
\end{tabular}

Notes: $\Delta$ Cognitive reports change in cognitive achievement at kindergarten entry for the model simulations (Model) and from impacts reported in the Head Start Impact Study (HSIS). The two columns supertitled Intent to Treat report the average change in cognitive achievement at kindergarten entry of being Head Start eligible (in the model) and the average change in cognitive skills at kindergarten entry for children who were offered Head Start services (in the HSIS). The two columns supertitled Treatment on the Treated report the average change in cognitive achievement at kindergarten entry of using Head Start (in the model) and the Bloom adjusted Intent to Treat estimate (in the HSIS). The column label Design refers to the two arms of randomization in the HSIS. The 4 year old cohort was a group of children randomized to receive Head Start or not at 4 years old. The 3 year old cohort consisted of a treatment and a delayed treatment control starting at 4 years old. I implement these design features in the model simulations by removing Head Start from the choice set for 4 year olds in the control counterfactual for the HS Impact Study 4 year olds design and by removing Head Start from the choice set of 3 year olds in the control counterfactual for the HS Impact Study 3 year olds design. 
Table D.2: Head Start Counterfactuals

Intent to Treat Cost Per Total Relative

\begin{tabular}{lccccc} 
Head Start $(H S)$ Counterfactual & $\Delta$ Cog & $\Delta$ LFP & Take-up & Child & Cost \\
\hline \hline 1. Remove Head Start & -0.15 & -0.03 & - & - & 1 \\
1. Remove HS: Cash Transfer $\$ 7,220$ & -0.13 & -0.10 & $100 \%$ & $\$ 7,220$ & 3.7 \\
2. HS Income Cutoff: $+\$ 10,000$ & 0.13 & 0.02 & $42.8 \%$ & $\$ 7,220$ & 3.4 \\
3. HS Income Cutoff: $+\$ 20,000$ & 0.16 & 0.03 & $47.9 \%$ & $\$ 7,220$ & 5.8 \\
4. HS Income Cutoff: $+\$ 40,000$ & 0.18 & 0.02 & $50.1 \%$ & $\$ 7,220$ & 9.6 \\
5. HS Income Cutoff: Universal & 0.21 & 0.02 & $55.6 \%$ & $\$ 7,220$ & 14.9 \\
\hline \hline
\end{tabular}

Notes: $\Delta$ Cognitive and $\Delta$ LFP are the average differences across treatment and baseline in cognitive skills and labor force participation for the Head Start eligible population (Intent to Treat). Take-up is the percentage using Head Start among eligibles. Cost per child is the average cost per child per year, which I set to $\$ 7,220$. The Head Start cash transfer is a six-month transfer that is half of the yearly cost per child in Head Start $(\$ 7,220)$. Total Cost is the total cost per year for the different Head Start program configurations relative to the total simulated cost of the baseline Head Start program. 
Table D.3: The Effect of Head Start Policies on the Black-White (BW) Achievement Gap

\begin{tabular}{cc}
$\% \Delta$ in \\
BW Gap & BW Gap \\
\hline \hline
\end{tabular}

Baseline gap at kindergarten entry $\quad-0.296$

Head Start Counterfactuals

1. Remove HS

2. Remove HS: Cash Transfer $\$ 3610$

$-0.324$

$-9.66$

3. HS Income Cutoff: $+\$ 10000$

$-0.307$

$-3.95$

4. HS Income Cutoff: $+\$ 20,000$

$-0.27$

8.51

5. HS Income Cutoff: $+\$ 40,000$

$-0.267$

9.78

6. HS Income Cutoff: Universal

$-0.284$

3.82

$-0.331$

$-12.11$

Notes: The Head Start counterfactuals are relative to closing the blackwhite achievement gap at kindergarten entry. The column $\% \Delta$ in BW Achievement Gap reports the percent change in the counterfactual black-white achievement gap relative to the simulated baseline black-white achievement gap for the Head Start counterfactuals. 
Table D.4: Subsidy Counterfactuals I

\begin{tabular}{|c|c|c|c|c|c|c|c|}
\hline \multirow{2}{*}{$\begin{array}{l}\text { Income } \\
\text { Cutoff }\end{array}$} & \multicolumn{5}{|c|}{ Intent to Treat } & \multirow{2}{*}{$\begin{array}{l}\text { Cost Per } \\
\text { Child }(\$)\end{array}$} & \multirow{2}{*}{$\begin{array}{c}\text { Total Cost } \\
\text { Relative to } \\
\text { Baseline }\end{array}$} \\
\hline & $\begin{array}{l}\text { Rate } \\
\text { Ceilino }\end{array}$ & Conay & A Connitive & $\triangle I F P$ & Take_In & & \\
\hline \multicolumn{8}{|l|}{ Baseline } \\
\hline$\$ 15,000$ & $\$ 3.9$ & $9 \%$ & 0.037 & 0.11 & $40.8 \%$ & 4,104 & 1 \\
\hline \multicolumn{8}{|c|}{ Vary Copay } \\
\hline$\$ 15,000$ & $\$ 3.9$ & $0 \%$ & 0.063 & 0.17 & $62.9 \%$ & 4,586 & 1.87 \\
\hline$\$ 15,000$ & $\$ 3.9$ & $10 \%$ & 0.037 & 0.1 & $39.6 \%$ & 3,960 & 0.93 \\
\hline$\$ 15,000$ & $\$ 3.9$ & $20 \%$ & 0.023 & 0.06 & $23.6 \%$ & 2,757 & 0.36 \\
\hline$\$ 15,000$ & $\$ 3.9$ & $30 \%$ & 0.016 & 0.04 & $10.4 \%$ & 1,854 & 0.11 \\
\hline \multicolumn{8}{|c|}{ Vary Rate Ceiling } \\
\hline$\$ 15,000$ & $\$ 1$ & $9 \%$ & 0.002 & 0.01 & $6.3 \%$ & 376 & 0.01 \\
\hline$\$ 15,000$ & $\$ 5$ & $9 \%$ & 0.045 & 0.14 & $44.9 \%$ & 5,353 & 1.49 \\
\hline$\$ 15,000$ & $\$ 10$ & $9 \%$ & 0.082 & 0.2 & $55.3 \%$ & 8,283 & 3.13 \\
\hline$\$ 15,000$ & $\$ 20$ & $9 \%$ & 0.086 & 0.23 & $56.3 \%$ & 9,223 & 3.7 \\
\hline \multicolumn{8}{|c|}{ Vary Income Cutoff } \\
\hline$\$ 5,000$ & $\$ 3.9$ & $9 \%$ & 0.094 & 0.22 & $29.6 \%$ & 4,085 & 0.08 \\
\hline$\$ 10,000$ & $\$ 3.9$ & $9 \%$ & 0.052 & 0.14 & $34 \%$ & 4,228 & 0.39 \\
\hline$\$ 15,000$ & $\$ 3.9$ & $9 \%$ & 0.037 & 0.11 & $40.8 \%$ & 4,104 & 1 \\
\hline$\$ 30,000$ & $\$ 3.9$ & $9 \%$ & 0.027 & 0.09 & $43.8 \%$ & 3,510 & 2.6 \\
\hline \multicolumn{8}{|c|}{ Targeted to Very Poor } \\
\hline$\$ 5,000$ & $\$ 20$ & $0 \%$ & 0.144 & 0.36 & $65.6 \%$ & 8,323 & 0.49 \\
\hline
\end{tabular}

The child care subsidy policy parameters are calibrated to averages across state level policy parameters. I use $\$ 15,000$ for the income cutoff, $\$ 3.90$ for the rate ceiling and $9 \%$ for the copay. $\Delta$ Cognitive and $\Delta$ LFP are the average differences across treatment and baseline in cognitive skills and labor force participation for the subsidy eligible population regardless of subsidy use (Intent to Treat). Take-up is the percentage using subsidies among the subsidy eligible population. Cost per child is the average subsidy payment per child per year net of copayments paid by the family. The total cost is the total cost per year net of copayments relative to the total simulated cost of the baseline subsidy program. 
Table D.5: Subsidy Counterfactuals II

\begin{tabular}{|c|c|c|c|c|c|c|c|}
\hline \multirow[b]{2}{*}{$\begin{array}{l}\text { Income } \\
\text { Cutoff }\end{array}$} & \multirow[b]{2}{*}{$\begin{array}{l}\text { Rate } \\
\text { Ceiling }\end{array}$} & \multirow[b]{2}{*}{ Copay } & \multicolumn{3}{|c|}{ Intent to Treat } & \multicolumn{2}{|c|}{ Eligibles } \\
\hline & & & $\Delta$ Cognitive & $\Delta$ Quality & $\Delta \mathrm{CCP}$ & $\begin{array}{l}\text { Quality: } \\
\text { Users }\end{array}$ & $\begin{array}{l}\text { Quality: } \\
\text { Non-Users }\end{array}$ \\
\hline \multicolumn{8}{|l|}{ Baseline } \\
\hline$\$ 15,000$ & $\$ 3.9$ & $9 \%$ & 0.037 & 0 & 0.15 & 0.06 & -0.02 \\
\hline \multicolumn{8}{|c|}{ Vary Copay } \\
\hline$\$ 15,000$ & $\$ 3.9$ & $0 \%$ & 0.063 & 0.01 & 0.24 & 0.05 & - \\
\hline$\$ 15,000$ & $\$ 3.9$ & $10 \%$ & 0.037 & 0.01 & 0.14 & 0.06 & -0.02 \\
\hline$\$ 15,000$ & $\$ 3.9$ & $20 \%$ & 0.023 & 0 & 0.08 & 0.06 & 0.02 \\
\hline$\$ 15,000$ & $\$ 3.9$ & $30 \%$ & 0.016 & 0 & 0.05 & 0.03 & 0.03 \\
\hline \multicolumn{8}{|c|}{ Vary Rate Ceiling } \\
\hline$\$ 15,000$ & $\$ 1$ & $9 \%$ & 0.002 & 0 & 0.01 & -0.04 & 0.05 \\
\hline$\$ 15,000$ & $\$ 5$ & $9 \%$ & 0.045 & 0.01 & 0.19 & 0.06 & -0.03 \\
\hline$\$ 15,000$ & $\$ 10$ & $9 \%$ & 0.082 & 0.02 & 0.3 & 0.08 & -0.02 \\
\hline$\$ 15,000$ & $\$ 20$ & $9 \%$ & 0.086 & 0.01 & 0.32 & 0.07 & -0.02 \\
\hline \multicolumn{8}{|c|}{ Vary Income Cutoff } \\
\hline$\$ 5,000$ & $\$ 3.9$ & $9 \%$ & 0.094 & 0.02 & 0.26 & 0.04 & -0.08 \\
\hline$\$ 10,000$ & $\$ 3.9$ & $9 \%$ & 0.052 & -0.01 & 0.19 & 0.06 & 0 \\
\hline$\$ 15,000$ & $\$ 3.9$ & $9 \%$ & 0.037 & 0 & 0.15 & 0.06 & -0.02 \\
\hline$\$ 30,000$ & $\$ 3.9$ & $9 \%$ & 0.027 & 0 & 0.1 & 0.07 & -0.01 \\
\hline
\end{tabular}

The child care subsidy policy parameters are calibrated to averages across state level policy parameters. I use $\$ 15,000$ for the income cutoff, $\$ 3.90$ for the rate ceiling and $9 \%$ for the copay. $\Delta$ Cognitive, $\Delta$ Quality and $\Delta \mathrm{CCP}$ are the average differences across treatment and baseline in cognitive skills, child care quality and child care participation for the subsidy eligible population (Intent to Treat). The two columns supertitled Eligibles shows the average quality for eligible subsidy users and eligible subsidy non-users. 
Table D.6: The Effect of Child Care Subsidies on the Black-White (BW) Achievement Gap

ב

Baseline Black-White Achievement Gap $\quad-0.2078$

\begin{tabular}{|c|c|c|c|c|}
\hline Income Cutoff & Rate Ceiling & Copay & BW Gap & $\begin{array}{c}\% \Delta \\
\text { BW Gap }\end{array}$ \\
\hline \multicolumn{5}{|c|}{ Baseline } \\
\hline$\$ 15000$ & $\$ 3.9$ & $9 \%$ & -0.2086 & -0.4 \\
\hline \multicolumn{5}{|l|}{ Vary Copay } \\
\hline$\$ 15,000$ & $\$ 3.9$ & $0 \%$ & -0.2102 & -1.2 \\
\hline$\$ 15,000$ & $\$ 3.9$ & $10 \%$ & -0.2068 & 0.5 \\
\hline$\$ 15,000$ & $\$ 3.9$ & $20 \%$ & -0.2064 & 0.6 \\
\hline$\$ 15,00$ & $\$ 3.9$ & $30 \%$ & -0.2069 & 0.4 \\
\hline \multicolumn{5}{|c|}{ Vary Rate Ceiling } \\
\hline$\$ 15,000$ & $\$ 1$ & $9 \%$ & -0.2083 & -0.3 \\
\hline$\$ 15,000$ & $\$ 5$ & $9 \%$ & -0.2108 & -1.4 \\
\hline$\$ 15,000$ & $\$ 10$ & $9 \%$ & -0.2052 & 1.3 \\
\hline$\$ 15,000$ & $\$ 20$ & $9 \%$ & -0.2062 & 0.8 \\
\hline \multicolumn{5}{|c|}{ Vary Income Cutoff } \\
\hline$\$ 5,000$ & $\$ 3.9$ & $9 \%$ & -0.2062 & 0.8 \\
\hline$\$ 10,000$ & $\$ 3.9$ & $9 \%$ & -0.2071 & 0.4 \\
\hline$\$ 15,000$ & $\$ 3.9$ & $9 \%$ & -0.2086 & -0.4 \\
\hline$\$ 30,000$ & $\$ 3.9$ & $9 \%$ & -0.2087 & -0.4 \\
\hline \multicolumn{5}{|c|}{ Targeted to Very Poor } \\
\hline$\$ 5,000$ & $\$ 20$ & $0 \%$ & -0.2042 & 1.7 \\
\hline
\end{tabular}

Notes: The subsidy counterfactuals are relative to closing the blackwhite achievement gap averaged across all periods. The difference between the two numbers reflects the gradual opening of the black-white achievement gap. In the column $\% \Delta$ in BW Achievement Gap, I report the percent change in the counterfactual black-white achievement gap relative to the simulated baseline black-white achievement gap for subsidy counterfactuals. 


\section{References}

[1] G. Adams and M. Rohacek. More than a work support? Issues around integrating child development goals into the child care subsidy system. Early Childhood Research Quarterly, 17(4):418-440, 2002.

[2] D. Almond and J. Currie. Human capital development before age five. Handbook of Labor Economics, 4:1315-1486, 2011.

[3] J.R. Behrman. Intrahousehold distribution and the family. Handbook of population and family economics, 1:125-187, 1997.

[4] D. Bellinger, A. Leviton, C. Waternaux, H. Needleman, and M. Rabinowitz. Longitudinal analyses of prenatal and postnatal lead exposure and early cognitive development. New England Journal of Medicine, 316(17):1037$1043,1987$.

[5] M.C. Berger and D.A. Black. Child care subsidies, quality of care, and the labor supply of low-income, single mothers. The Review of Economics and Statistics, 74(4):635-642, 1992.

[6] R. Bernal. The effect of maternal employment and child care on childrens cognitive development. International Economic Review, 49(4):1173-1209, 2008.

[7] R. Bernal, M. Keane, and A.R.C.F. Fellow. Child care choices and childrens cognitive achievement: the case of single mothers. manuscript, Northwestern University and Yale University, 2006.

[8] R. Bernal and M.P. Keane. Quasi-structural estimation of a model of childcare choices and child cognitive ability production. Journal of Econometrics, 156(1):164-189, 2010.

[9] R. Bernal and M.P. Keane. Child care choices and childrens cognitive achievement: The case of single mothers. Journal of Labor Economics, 29(3):459-512, 2011.

[10] D. Blau and J. Currie. Pre-school, day care, and after-school care: Who's minding the kids? Handbook of the Economics of Education, 2:1163-1278, 2006.

[11] D. Blau and E. Tekin. The determinants and consequences of child care subsidies for single mothers in the USA. Journal of Population Economics, 20(4):719-741, 2007. 
[12] D.M. Blau. The quality of child care: An economic perspective. The economics of child care, pages 145-174, 1991.

[13] D.M. Blau. The production of quality in child care centers. Journal of Human Resources, pages 354-387, 1997.

[14] D.M. Blau. The effect of child care characteristics on child development. Journal of Human Resources, pages 786-822, 1999.

[15] D.M. Blau. Child care subsidy programs. NBER Working Paper, 2000.

[16] D.M. Blau and A.P. Hagy. The demand for quality in child care. Journal of Political Economy, 106(1):104-146, 1998.

[17] D.M. Blau and H.N. Mocan. The supply of quality in child care centers. Review of Economics and Statistics, 84(3):483-496, 2002.

[18] D.M. Blau and P.K. Robins. Child-care costs and family labor supply. The Review of Economics and Statistics, pages 374-381, 1988.

[19] M. Burchinal, C. Howes, R. Pianta, D. Bryant, D. Early, R. Clifford, and O. Barbarin. Predicting Child Outcomes at the End of Kindergarten from the Quality of Pre-Kindergarten Teacher-Child Interactions and Instruction. Applied Developmental Science, 12(3):140-153, 2008.

[20] M.R. Burchinal, J.E. Roberts, R. Riggins Jr, S.A. Zeisel, E. Neebe, and D. Bryant. Relating quality of center-based child care to early cognitive and language development longitudinally. Child Development, 71(2):339-357, 2000.

[21] P. Carneiro, J.J. Heckman, and National Bureau of Economic Research. Human capital policy. National Bureau of Economic Research, 2003.

[22] R. Connelly. The effect of child care costs on married women's labor force participation. The Review of Economics and Statistics, pages 83-90, 1992.

[23] A. Crawford. The Impact of Child Care Subsidies on Single Mothers' Work Effort. Review of Policy Research, 23(3):699-711, 2006.

[24] D.A. Crosby, L. Gennetian, and A.C. Huston. Child care assistance policies can affect the use of center-based care for children in low-income families. Applied Developmental Science, 9(2):86-106, 2005.

[25] F. Cunha. A Time to Plant and a Time to Reap, 2006.

[26] F. Cunha and J. Heckman. The technology of skill formation. American Economic Review, 97(2):31-47, 2007. 
[27] F. Cunha and J.J. Heckman. Formulating, identifying and estimating the technology of cognitive and noncognitive skill formation. Journal of Human Resources, 43(4):738-782, 2008.

[28] J. Currie and M. Neidell. Getting Inside the'Black Box'of Head Start Quality: What Matters and What Doesn't? NBER working paper, 2003.

[29] J. Currie and D. Thomas. Does Head Start make a difference? The American Economic Review, 85(3):341-364, 1995.

[30] J. Currie and D. Thomas. Early test scores, socioeconomic status and future outcomes, 1999.

[31] J.M. Currie. The invisible safety net: protecting the nation's poor children and families. Princeton Univ Pr, 2008.

[32] W. Damon and R.M. Lerner. Handbook of child psychology. Wiley, 2006.

[33] N. Datta Gupta and M. Simonsen. Non-cognitive child outcomes and universal high quality child care. Journal of Public Economics, 2009.

[34] D. Del Boca, C. Flinn, and M. Wiswall. Household Choices and Child Development. IZA, 2010.

[35] G.J. Duncan. Modeling the impacts of child care quality on children's preschool cognitive development. Child Development, 74(5):1454-1475, 2003.

[36] G.J. Duncan, J. Ludwig, and K.A. Magnuson. Reducing poverty through preschool interventions. The Future of Children, pages 143-160, 2007.

[37] Gorman K. Martorell R. Engle, P.L. and E. Pollitt. The incap longitudinal study: Infant and preschool psychological development. Food and Nutrition Bulletin, 14(3):201-214, 1992.

[38] C.K.C. Ficano, L.A. Gennetian, and P.A. Morris. Child Care Subsidies and Employment Behavior Among Very-Low-Income Populations in Three States. Review of Policy Research, 23(3):681-698, 2006.

[39] N.D. Forry. The impact of child care subsidies on low-income single parents: An examination of child care expenditures and family finances. Journal of family and economic issues, 30(1):43-54, 2009.

[40] R.G. Fryer Jr and S.D. Levitt. Understanding the black-white test score gap in the first two years of school. Review of Economics and Statistics, 86(2):447-464, 2004. 
[41] R.G. Fryer Jr and S.D. Levitt. Testing for racial differences in the mental ability of young children, 2006.

[42] C. Gibbs, J. Ludwig, and D.L. Miller. Does head start do any lasting good? Technical report, National Bureau of Economic Research, 2011.

[43] WT Gormley Jr, T. Gayer, D. Phillips, and B. Dawson. The effects of universal pre-K on cognitive development. Developmental Psychology, 41:872-884, 2005.

[44] A.P. Hagy. The demand for child care quality: An hedonic price theory approach. Journal of Human Resources, 33(3):683-710, 1998.

[45] K.M. Harris, R.K. Raley, and R.R. Rindfuss. Family Configurations and Child-Care Patterns: Familes with Two or More Preschool-Age Children. Social Science Quarterly, 83(2):455-471, 2002.

[46] J. Heckman and B. Singer. A method for minimizing the impact of distributional assumptions in econometric models for duration data. Econometrica: Journal of the Econometric Society, pages 271-320, 1984.

[47] J.J. Heckman. Effects of child-care programs on women's work effort. The Journal of Political Economy, pages 136-163, 1974.

[48] J.J. Heckman. Micro data, heterogeneity, and the evaluation of public policy: Nobel lecture. Journal of Political Economy, pages 673-748, 2001.

[49] J.J. Heckman. Skill formation and the economics of investing in disadvantaged children. Science, 312(5782):1900, 2006.

[50] J.J. Heckman, R.J. LaLonde, and J.A. Smith. The economics and econometrics of active labor market programs. Handbook of labor economics, 3:18652097, 1999.

[51] J.J. Heckman and T.E. MaCurdy. A life cycle model of female labour supply. The Review of Economic Studies, 47(1):47-74, 1980.

[52] S.W. Helburn. Cost, quality and child outcomes in child care centers. technical report, public report, and executive summary. 1995.

[53] S.W. Helburn and C. Howes. Child care cost and quality. The Future of Children, 6(2):62-82, 1996.

[54] C.M. Herbst. Who are the eligible non-recipients of child care subsidies? Children and Youth Services Review, 30(9):1037-1054, 2008. 
[55] C.M. Herbst and B.S. Barnow. Close to home: A simultaneous equations model of the relationship between child care accessibility and female labor force participation. Journal of Family and Economic Issues, 29(1):128-151, 2008.

[56] C.M. Herbst and E. Tekin. Child care subsidies and child development. Economics of Education Review, 2010.

[57] C.M. Herbst and E. Tekin. The impact of child care subsidies on child wellbeing: Evidence from geographic variation in the distance to social service agencies. Technical report, National Bureau of Economic Research, 2010.

[58] V.J. Hotz and M. Xiao. The impact of regulations on the supply and quality of care in child care markets. The American Economic Review, 101(5):1775$1805,2011$.

[59] S. Imai and M.P. Keane. Intertemporal labor supply and human capital accumulation*. International Economic Review, 45(2):601-641, 2004.

[60] S. James-Burdumy. The effect of maternal labor force participation on child development. Journal of Labor Economics, 23(1):177-211, 2005.

[61] M.P. Keane and K.I. Wolpin. The solution and estimation of discrete choice dynamic programming models by simulation and interpolation: Monte Carlo evidence. The Review of Economics and Statistics, pages 648-672, 1994.

[62] M.P. Keane and K.I. Wolpin. The career decisions of young men. Journal of Political Economy, 105(3):473-522, 1997.

[63] M.P. Keane and K.I. Wolpin. The Role of Labor and Marriage Markets, Preference Heterogeneity and the Welfare System in the Life Cycle Decisions of Black, Hispanic and White Women. Unpublished manuscript, University of Pennsylvania, 2006.

[64] M.P. Keane and K.I. Wolpin. The role of labor and marriage markets, preference heterogeneity and the welfare system in the life cycle decisions of black, hispanic and white women. International Economic Review, 51(3):851-892, 2010.

[65] J. Kimmel. The effectiveness of child-care subsidies in encouraging the welfare-to-work transition of low-income single mothers. The American Economic Review, 85(2):271-275, 1995.

[66] J. Kimmel. Child care costs as a barrier to employment for single and married mothers. Review of Economics and Statistics, 80(2):287-299, 1998. 
[67] E. Kisker and R. Maynard. Quality, cost, and parental choice of child care. The economics of child care, pages 127-144, 1991.

[68] M.E. Lamb. Nonparental child care: Context, quality, correlates, and consequences. In: Damon W, Sigel IE, Renninger KA, eds. Handbook of child psychology Vol. 4: Child psychology in practice., pages 73-133, 1998.

[69] J.I. Layzer and B.D. Goodson. The" Quality" of Early Care and Education Settings: Definitional and Measurement Issues. Evaluation Review, 30(5):556, 2006.

[70] A. Leibowitz. Home investments in children, 1974.

[71] J.M. Love, P.Z. Schochet, and A.L. Meckstroth. Are they in any real danger? What research doesand doesnttell us about child care quality and childrens well-being. Princeton, NJ: Mathematica Policy Research, 1996.

[72] D. McFadden. A method of simulated moments for estimation of discrete response models without numerical integration. Econometrica: Journal of the Econometric Society, pages 995-1026, 1989.

[73] C. Michalopoulos, P.K. Robins, and I. Garfinkel. A structural model of labor supply and child care demand. Journal of Human Resources, 27(1):166-203, 1992.

[74] R.J. Murnane, R.A. Maynard, and J.C. Ohls. Home resources and children's achievement. The Review of Economics and Statistics, 63(3):369-377, 1981.

[75] D. Neal. Why has black-white skill convergence stopped? Handbook of the Economics of Education, 1:511-576, 2006.

[76] D.A. Neal and W.R. Johnson. The role of premarket factors in black-white wage differences. The Journal of Political Economy, 104(5):869-895, 1996.

[77] D.A. Phillips, M. Voran, E. Kisker, C. Howes, and M. Whitebook. Child care for children in poverty: Opportunity or inequity? Child Development, 65(2):472-492, 1994.

[78] M. Puma, S. Bell, R. Cook, C. Heid, M. Lopez, N. Zill, G. Shapiro, P. Broene, D. Mekos, M. Rohacek, et al. Head Start impact study: First year findings. Administration for Children and Families, Department of Health and Human Services, Washington, DC, 2005.

[79] D.C. Ribar. Child care and the labor supply of married women: Reduced form evidence. Journal of Human Resources, 27(1):134-165, 1992. 
[80] J.L. Rodgers, H.H. Cleveland, E. van den Oord, and D.C. Rowe. Resolving the debate over birth order, family size, and intelligence. American Psychologist, 55(6):599, 2000.

[81] M.R. Rosenzweig and T.P. Schultz. Estimating a household production function: Heterogeneity, the demand for health inputs, and their effects on birth weight. The Journal of Political Economy, 91(5):723-746, 1983.

[82] K. Schulman and H. Blank. State child care assistance policies 2007: Some steps forward, more progress needed. Retrieved online, November, 19:2007, 2007.

[83] E. Tekin. Child care subsidy receipt, employment, and child care choices of single mothers. Economics Letters, 89(1):1-6, 2005.

[84] E. Tekin. Single Mothers working at Night: Standard Work and Child Care Subsidies. Economic Inquiry, 45(2):233-250, 2007.

[85] P.E. Todd and K.I. Wolpin. On the specification and estimation of the production function for cognitive achievement. The Economic Journal, 113(485):3-33, 2003.

[86] P.E. Todd and K.I. Wolpin. Assessing the impact of a school subsidy program in mexico: Using a social experiment to validate a dynamic behavioral model of child schooling and fertility. The American economic review, 96(5):1384$1417,2006$.

[87] P.E. Todd and K.I. Wolpin. The production of cognitive achievement in children: Home, school, and racial test score gaps. Journal of Human capital, 1(1):91-136, 2007.

[88] D.L. Vandell and B. Wolfe. Child care quality: Does it matter and does it need to be improved. Commissioned Report to the US Department of Health and Human Services, 2000.

[89] J.R. Walker. Public policy and the supply of child care services. The economics of child care, pages 51-77, 1991.

[90] U.S.H. Ways. Means Committee. 2004 Green Book Background Material and Data on the Programs within the Jurisdiction of the Committee on Ways and Means. Washington, DC: US Government Printing Office, 2004.

[91] E. Zigler and S.J. Styfco. The Head Start Debates. Brookes Publishing Company, page 590, 2004. 